\title{
A multilayer physically based snowpack model simulating direct and indirect radiative impacts of light-absorbing impurities in snow
}

\author{
Francois Tuzet $^{1,2}$, Marie Dumont ${ }^{1}$, Matthieu Lafaysse ${ }^{1}$, Ghislain Picard $^{2}$, Laurent Arnaud ${ }^{2}$, Didier Voisin ${ }^{2}$, \\ Yves Lejeune $^{1}$, Luc Charrois ${ }^{1}$, Pierre Nabat ${ }^{3}$, and Samuel Morin ${ }^{1}$ \\ ${ }^{1}$ Meteo-France-CNRS, CNRM UMR 3589, Centre d'Etudes de la Neige, Grenoble, France \\ ${ }^{2}$ UGA-CNRS, Institut des Geosciences de l'Environnement (IGE) UMR5001, Grenoble, France \\ ${ }^{3}$ Meteo-France-CNRS, CNRM UMR 3589, GMGEC/MOSCA, Toulouse , France
}

Correspondence to: Francois Tuzet (francois.tuzet@meteo.fr)

Received: 19 May 2017 - Discussion started: 8 June 2017

Revised: 29 September 2017 - Accepted: 7 October 2017 - Published: 20 November 2017

\begin{abstract}
Light-absorbing impurities (LAIs) decrease snow albedo, increasing the amount of solar energy absorbed by the snowpack. Its most intuitive and direct impact is to accelerate snowmelt. Enhanced energy absorption in snow also modifies snow metamorphism, which can indirectly drive further variations of snow albedo in the near-infrared part of the solar spectrum because of the evolution of the nearsurface snow microstructure. New capabilities have been implemented in the detailed snowpack model SURFEX/ISBACrocus (referred to as Crocus) to account for impurities' deposition and evolution within the snowpack and their direct and indirect impacts. Once deposited, the model computes impurities' mass evolution until snow melts out, accounting for scavenging by meltwater. Taking advantage of the recent inclusion of the spectral radiative transfer model TARTES (Two-stream Analytical Radiative TransfEr in Snow model) in Crocus, the model explicitly represents the radiative impacts of light-absorbing impurities in snow. The model was evaluated at the Col de Porte experimental site (French Alps) during the 2013-2014 snow season against in situ standard snow measurements and spectral albedo measurements. In situ meteorological measurements were used to drive the snowpack model, except for aerosol deposition fluxes. Black carbon (BC) and dust deposition fluxes used to drive the model were extracted from simulations of the atmospheric model ALADIN-Climate. The model simulates snowpack evolution reasonably, providing similar performances to our reference Crocus version in terms of snow depth, snow water equivalent (SWE), near-surface specific surface area (SSA) and shortwave albedo. Since the reference empirical
\end{abstract}

albedo scheme was calibrated at the Col de Porte, improvements were not expected to be significant in this study. We show that the deposition fluxes from the ALADIN-Climate model provide a reasonable estimate of the amount of lightabsorbing impurities deposited on the snowpack except for extreme deposition events which are greatly underestimated. For this particular season, the simulated melt-out date advances by 6 to 9 days due to the presence of light-absorbing impurities. The model makes it possible to apportion the relative importance of direct and indirect impacts of lightabsorbing impurities on energy absorption in snow. For the snow season considered, the direct impact in the visible part of the solar spectrum accounts for $85 \%$ of the total impact, while the indirect impact related to accelerated snow metamorphism decreasing near-surface specific surface area and thus decreasing near-infrared albedo accounts for $15 \%$ of the total impact. Our model results demonstrate that these relative proportions vary with time during the season, with potentially significant impacts for snowmelt and avalanche prediction.

\section{Introduction}

Light-absorbing impurities (LAIs) in snow increase the absorption of solar radiation in the visible range, warming up the snowpack and accelerating snowmelt (e.g., Warren and Wiscombe, 1980; Jacobson, 2004). Snow albedo can be affected by a wide variety of impurities such as mineral dust (Painter et al., 2010), black carbon (BC) from combustion 
sources (Flanner et al., 2007), volcanic ash (Conway et al., 1996), soil organics (Takeuchi, 2002), algae, and other biological organisms and constituents (Cook et al., 2017). The concentrations of these impurities in snow are determined by their mixing ratio in precipitation (wet deposition), by the amount deposited to the surface through dry deposition and by impurity redistribution in the snowpack via postdepositional processes such as wind-driven drifting, wind pumping, snow sublimation and scavenging during snowmelt which contributes to a decrease in the surface concentration of LAI at melt time (Doherty et al., 2013). Besides impurities, which operate mostly in the visible part of the solar spectrum, the physical properties of the snow microstructure also influence snow albedo and light penetration in snow in particular in the near infrared. This concerns, in particular, density and specific surface area (SSA; Domine et al., 2006). Therefore, addressing the impact of light-absorbing impurities in snow must also take into account physical snow properties. Indeed, the radiative impact of LAIs on snow can be separated in two parts - direct and indirect impacts (Painter et al., 2007). LAIs in snow accelerate snowmelt through albedo feedbacks. The darkening of the snow surface reduces albedo in the visible range (direct impact). In turn, this leads to an acceleration of the metamorphism which further reduces albedo by accelerating near-surface SSA decrease (indirect impacts). This induces at least two positive snow albedo feedbacks. First, snow albedo in the near-infrared decreases with SSA (even in absence of LAIs due to a decrease in the ratio between scattering and absorption coefficients; Warren, 1982). Secondly, for a given LAI concentration in snow, LAI radiative forcing increases as SSA decreases (Doherty et al., 2013).

The LAI content in snow has been the subject of numerous measurements. For instance, Carmagnola et al. (2013), Aoki et al. (2014) and Polashenski et al. (2015) gathered information on the snow LAI content (insoluble soot and dust) over the Greenland Ice Sheet. Doherty et al. (2010) also focused on the radiative impact of LAIs on arctic snow showing, in particular, that non-BC constituents (e.g., organic carbon) are responsible for up to $50 \%$ of absorption by LAIs in the Arctic. Bisiaux et al. (2012) presents a review of BC deposition in the Antarctic over the last century derived from ice core analysis. LAI content in seasonal snowpacks has also been the subject of several studies. Painter et al. (2013b) and Skiles et al. (2015) pointed out that, in the upper Colorado basin, dust strongly affects snow radiative forcing and can advance total melt-out by up to 50 days. Sterle et al. (2013) showed how the impurity content evolves with respect to snow metamorphism and melt, notably that the accumulation of $\mathrm{BC}$ and dust on the top of the snowpack at the end of the season plays an important role in the radiative forcing of the Sierra Nevada's spring snowpack. In the European Alps, the two types of LAIs suspected to have the most significant influence on snowpack evolution are BC and mineral dust (Di Mauro et al., 2015). Table 2 in Libois et al. (2013) summarized measurements of $\mathrm{BC}$ concentration in snow in different sites in the Alps, highlighting that $\mathrm{BC}$ is present in snow even in sites remote from the main BC sources. Painter et al. (2013a) even estimated BC to be one of the causes of the end of the Little Ice Age in the Alps. Mineral dust depositions are also frequently observed across the European mountain ranges, giving some snow layers a reddish or yellowish color. This is a well-known phenomenon suspected to play an important role in snow-covered surface radiative forcing (De Angelis and Gaudichet, 1991; Di Mauro et al., 2015). Saharan dust depositions, hereafter referred to as dust outbreaks, are very sporadic events mostly occurring from April to August (Varga et al., 2014). They can last only a few hours and drop significant amounts at once, creating a strong discontinuity within the vertical profile of snowpack impurity content. This last phenomenon is suspected to affect snow metamorphism and eventually snowpack stability (Landry et al., 2014).

Several snow radiative transfer models accounting for LAI impacts have been developed over the last decades. They provide estimates of spectrally resolved snow albedo and light penetration in snow for given physical properties of snow and light-absorbing content with various levels of detail. Warren and Wiscombe (1980) and Wiscombe and Warren (1980) established a snow spectral albedo model taking into account the impact of BC and dust. Flanner and Zender (2005) and Flanner et al. (2007) developed another snow spectral radiative model called SNICAR (Snow, Ice, and Aerosol Radiation model) based on Wiscombe and Warren (1980) theory and on the two-stream multilayer radiative approximation (Toon et al., 1989). The SNICAR model accounts for both the size distribution of LAIs and their location relative to the ice matrix (internal or external mixture). In Carmagnola et al. (2013) and Ginot et al. (2014), DISORT (discrete ordinate radiative transfer model; Stamnes et al., 1988) was used to compute snow radiative properties in the presence of both internally or externally mixed LAIs. Aoki et al. (2011) developed the physically based snow albedo model (PBSAM) which computes the spectral albedo and solar heating profile within a multilayer snowpack. In all the previously introduced radiative transfer models, radiative properties of snow corresponded to spherical ice particles. Kokhanovsky and Zege (2004) pointed out that considering snow as spherical particles leads to some errors in the computation of snow radiative properties. They formulated the asymptotic analytical radiative transfer (AART) theory providing analytical formulations for a vertically homogeneous snowpack with nonspherical snow particles. This theory has been used in the Two-stream Analytical Radiative TransfEr in Snow model (TARTES; Libois et al., 2013) to compute light penetration and energy absorption in a multilayer snowpack containing LAIs based on the two-stream and $\delta$-Eddington approximations. Malinka (2014) developed a theory to compute spectral radiative properties of a porous material based on the chord length distribution within the snow. This theory was applied 
to different samples of arctic snow and sea ice snow in Malinka et al. (2016), providing a good estimation of snow spectral albedo in the visible and near-infrared wavelength range. Recently, Cook et al. (2017) implemented a radiative transfer model to compute the effect of "red snow algae" on snow spectral albedo. They used TARTES to compute the spectral albedo of snow containing different types of algae and showed that the impact of algae on snowmelt can be greater than that of $\mathrm{BC}$ in areas favorable to algae accumulations.

In order to accurately simulate the radiative properties of an evolving snowpack and to account for the albedo feedbacks, it is necessary to couple radiative transfer models with detailed snowpack evolution models. Coupling intermediate complexity snowpack models accounting for the deposition and fate of LAIs with radiative transfer models was achieved in a few pioneering studies, which demonstrated that LAI deposition was a major process operating on climate timescales on global and regional geographical scales. Krinner et al. (2006) showed how dust deposition on seasonal snow cover could have impacted northern Asia ice cover during the last glacial maximum, using a simple yet pragmatic representation of dust deposition in snow and its impact within the LMDZ4 global climate model. Ménégoz et al. (2014) refined and applied the same land surface model over more recent time periods in order to address the impact of black carbon deposition in snow in the Himalaya region. Flanner et al. (2007) coupled the snow radiative transfer model SNICAR to a snowpack scheme of the Community Atmosphere Model global climate model, explicitly simulating BC emissions and transport. This study highlighted the importance of BC in global snow-covered surface radiative forcing, showing that the inclusion of $\mathrm{BC}$ in snow leads to a global annual mean equilibrium warming up to $0.15^{\circ}$. However, the most detailed snowpack models do not, hitherto, explicitly account for LAI deposition and impact. Initial versions of SURFEX/ISBACrocus (referred to hereafter as Crocus) (Brun et al., 1992; Vionnet et al., 2012) and SNOWPACK (Lehning et al., 2002) multilayer detailed snowpack models mostly use empirical albedo decay equations, which do not explicitly account for the deposition of LAI, making them incapable of explicitly addressing LAI-snow physics feedbacks. Jacobi et al. (2015) implemented a radiative transfer scheme simulating dust and BC effects on a Himalayan snowpack simulated with the detailed snowpack model Crocus, but in their study the impurity concentration was assumed to be similar in all snow layers and constant over the season. Niwano et al. (2012) implemented a multilayer snowpack model integrating PBSAM. This model called Snow Metamorphism and Albedo Process (SMAP) computes radiative properties of an evolving snowpack in which impurities do not evolve; their concentrations are prescribed to field-measured values.

Recently, Skiles (2014) modified the snowpack model SNOWPACK to track the evolution of dust layers by introducing markers indicating the concentration of dust in each layer. The author implemented a sequential coupling between this snowpack model and SNICAR, which was run offline. At each time step, the snowpack model computes physical properties needed by SNICAR to compute the snow broadband albedo offline. This albedo is then reinjected into SNOWPACK at the next time step. This is one of the first attempts to make LAIs evolve inside the snowpack, providing the realistic surface LAI content of the snowpack throughout the season. The model they developed computes snowpack evolution under a prescribed dust stratigraphy but does not allow driving the model with atmospheric conditions, implying regular LAI concentrations measurements. Moreover, only the broadband albedo is reinjected into SNOWPACK regardless of the absorption profile, which has been proved to have a strong impact on the temperature profile and in turn on near-surface metamorphism (Libois et al., 2014; Flanner and Zender, 2005; Picard et al., 2016a). Nevertheless, this approach makes it possible to apportion the relative importance of direct and indirect impacts of light-absorbing impurities on energy absorption in snow on a seasonal snowpack. This study shows that, in the upper Colorado basin, $80 \%$ of LAI radiative forcing is due to the direct impact as opposed to $20 \%$ for the indirect impacts, implying that modeling only the snow darkening by LAIs underestimates their impact by $20 \%$.

In order to bridge the gap between detailed snowpack models and LAI deposition, evolution mechanisms and impacts, we implemented LAI deposition and evolution laws in the detailed multilayer snowpack model Crocus, thereby expanding the reach of such models into assessments of the subtle interplays between snow physics and LAI radiative properties. Taking advantage of the recent inclusion and coupling of the spectral radiative transfer model TARTES (Libois et al., 2015; Charrois et al., 2016) in Crocus, we extended the model capabilities in order to represent LAI deposition and fate within the snowpack and their direct and indirect impacts on the snowpack physical properties. In this study, the Crocus model takes typical meteorological driving data required for land surface models measured in the field, complemented by time series of LAI deposition fluxes (BC and dust) extracted from simulations with the ALADINClimate atmospheric model (Nabat et al., 2015). Our recent developments on the Crocus model were evaluated for the snow season 2013-2014 at the Col de Porte experimental site (Morin et al., 2012a). The results of different simulations with the new developments as well as the original albedo scheme in Crocus are compared with in situ field measurements. Finally, the apportionment between direct and indirect impacts of LAIs is estimated. Section 2 details the new developments implemented in the Crocus snowpack model and the setup of the present study. Section 3 introduces the data and methods used to obtain our results and evaluate the model. Finally, the model evaluation and the estimation of the direct and indirect impacts of LAIs are presented in Sect. 4 and discussed in Sect. 5. 


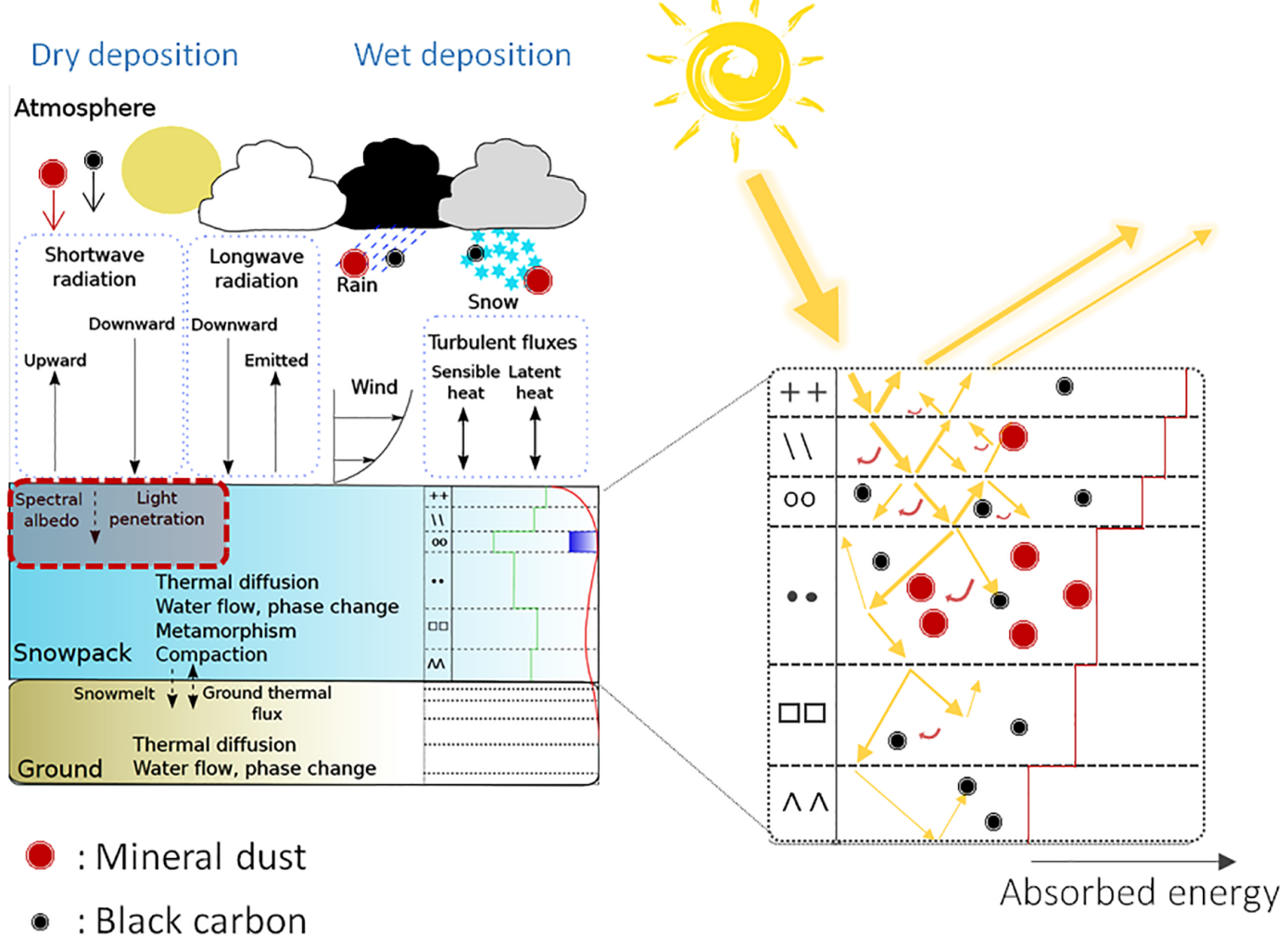

Figure 1. Description of the detailed snowpack model Crocus including an explicit representation of LAI deposition and evolution.

\section{Model description}

The multilayer detailed snowpack model Crocus (Brun et al., $1989,1992)$ represents the evolution of the snowpack due to its interactions with the atmosphere and the ground. Its input variables are air temperature, specific humidity and wind speed at a known height above ground; direct and diffuse shortwave and longwave incoming radiation; and precipitation rate, split between rain and snow. For more details about the snowpack model, a full description of its structure can be found in Vionnet et al. (2012). In the following, we describe the new developments that have been implemented to include LAI-snow interaction processes which are summarized in Fig. 1.

\subsection{LAI representation in Crocus}

Crocus is a Lagrangian model based on numerical snow layers; the snowpack is divided into several layers (up to 50 typically) considered to have homogeneous physical properties (Vionnet et al., 2012). In order to represent the deposition and the evolution of LAIs in Crocus, we created a new prognostic variable corresponding to the mass of LAIs present in each layer. For each Crocus layer, this variable is a onedimension array representing the mass content of different types of LAI. The model can handle a user-defined number of impurity types characterized by their optical and scavenging properties. In the present study we only focus on two types of LAIs (BC and mineral dust). Deposition and evolution within the snowpack follow several processes, as described below.

\subsubsection{LAI deposition}

Impurities can be deposited in the snow by two main processes (e.g., Aoki et al., 2006). They can be wet deposited - i.e., atmospheric aerosol particles are scavenged during a precipitation event. Particles present inside or below the clouds are scavenged by hydrometeors (e.g., rain drops or snow flakes) and deposited on the surface. This deposition mode is represented by scaling LAI content in case of precipitation to the value of the wet deposition flux $W_{i}$ expressed in $\mathrm{g} \mathrm{m}^{-2} \mathrm{~s}^{-1}$. In case of precipitation (solid or liquid), for each type $(i)$ of LAI, the mass contained in the precipitation $M_{p, i}$ expressed in $\mathrm{g} \mathrm{m}^{-2}$ is given by

$M_{p, i}=W_{i} \times \delta t$,

where $\delta t$ is the interval time step of the model in seconds. In case of snowfall, a new layer of fresh snow is created. The wet-deposited impurity amount is initially assigned to this new layer. In case of rain, the mass of impurity is initially assigned to the uppermost layer. 
They can also be dry-deposited by sedimentation or turbulent diffusion, leading to the deposition of aerosol particles on the ground even without precipitation. The parameterization implemented in Crocus considers that the dry deposition affects the near-surface snow layers with an exponential decay to take into account wind pumping which buries a fraction of the dry-deposited particles by circulating air into the uppermost snow layers. The mass distribution is calculated as follows for each layer $(l)$ and each type $(i)$ of LAI:

$$
M_{t+\delta t, l, i}=M_{t, l, i}+\frac{D_{i} \times \delta t \times e^{-\left(z_{l} / h\right)}}{\sum_{k=1}^{N} e^{-\left(z_{k} / h\right)} \Delta z_{k}} .
$$

Here, $M_{t, l, i}$ and $M_{t+\delta t, l, i}$ represent the mass of impurity type $i$ in $\mathrm{g} \mathrm{m}^{-2}$ in the layer $l$ at the beginning and end of the time step $\delta t, D_{i}$ is the dry deposition flux expressed in $\mathrm{g} \mathrm{m}^{-2} \mathrm{~s}^{-1}$ and $h$ is the user-defined $e$-folding depth characterizing the decrease rate of the impurity distribution with depth. Here $z_{l}$ is the depth of the layer $l$ and $z_{k}$ is the depth of the layer $\mathrm{k}, \mathrm{N}$ being the total number of Crocus layers. We assume the depth value of a layer to be the distance between the snowpack surface and the middle of this layer. The default value for $h$ is set to $5 \mathrm{~mm}$ according to the range of value in Clifton et al. (2008), which shows that wind-pumping affects between 1 and $10 \mathrm{~mm}$ of the snowpack surface depending on snow and atmospheric properties. As the typical thickness of the surface layer in Crocus is close to $1 \mathrm{~cm}$, this value of $h$ implies that most of the LAIs are initially deposited in the uppermost layer.

\subsubsection{LAI evolution within the snowpack}

\section{Handling of layers}

Crocus manages the layers to keep their numbers under a prescribed maximum value. When there are too many layers, two layers having similar microstructure properties can merge and the properties of the newly created layer are recalculated (see details in Charrois et al., 2016, or Vionnet et al., 2012). Concerning LAI content, the impurity mass of the new layer is the sum of the impurity mass of the two old layers.

On the contrary, when there are fewer layers than the optimum value computed by Crocus, a thick layer $(t)$ can be split into two different layers. For each of the newly created layers (n), the impurity mass is apportioned according to their snow water equivalent (SWE):

$M_{n}=M_{t} \times \frac{\mathrm{SWE}_{n}}{\mathrm{SWE}_{t}}$,

with $M_{n}$ and $M_{t}$ being respectively the impurity mass of the newly created and the initial layers in $\mathrm{g} \mathrm{m}^{-2}$ and with $\mathrm{SWE}_{n}$ and $\mathrm{SWE}_{t}$ being the SWE of the newly created and the initial thick layer in $\mathrm{kg} \mathrm{m}^{-2}$.
If a snow layer completely disappears (e.g., due to total melt or sublimation), its impurity content is transferred to the layer below, leading to an accumulation of LAI on the top of the snowpack during melt time. This enrichment process has been widely observed (e.g., Skiles, 2014; Yang et al., 2015). If the disappearing layer is the basal one, its impurity content is discarded by the model.

\section{Scavenging}

It has been established that some LAI types can be partially scavenged with percolating water during melt time (e.g., Flanner et al., 2007; Doherty et al., 2013; Sterle et al., 2013; Yang et al., 2015). When liquid water percolates into the snowpack, it can carry part of its impurity mass to the layer below. In the current version of Crocus, water percolation is handled following a simple and conceptual bucket approach (Lafaysse et al., 2017). Each layer ( $l$ ) is seen as a homogeneous reservoir containing a given volumetric liquid water content $W_{\text {liq }, l}$. For each layer a maximum volumetric liquid water holding capacity $W_{\text {liqmax }, l}$ is defined as a percentage of the pore volume. If $W_{\text {liq, } l}$ exceeds $W_{\text {liqmax }, l}$, the excess water $F_{\text {liq, } l}$ drains to the underlying layer.

Similarly to Flanner et al. (2007), we assume an LAI inclusion in meltwater proportional to its mass mixing ratio multiplied by a scavenging factor. Therefore, a scavenging coefficient $C_{\text {scav }, i}$, adjustable for each impurity type $(i)$, has been introduced in the model. In case of water percolation, for each layer $(l)$ the scavenged mass $M_{\mathrm{scav}, i, l}$ is calculated with

$M_{\mathrm{scav}, i, l}=F_{\mathrm{liq}, l} \times C_{\mathrm{scav}, i, l} \times \frac{M_{\mathrm{tot}, i, l}}{\mathrm{SWE}_{l}}$,

where $F_{\text {liq }, l}$ is the mass of water leaving the layer $l$ in $\mathrm{kg} \mathrm{m}^{-2}$ and $M_{\mathrm{tot}, i, l} / \mathrm{SWE}_{l}$ the impurity mixing ratio, i.e., the ratio between the total mass of impurity of type $i$ in the layer $l$ in $\mathrm{kg} \mathrm{m}^{-2}$ and the total SWE of the layer in $\mathrm{kg} \mathrm{m}^{-2}$.

In the present study, we disabled scavenging by default, implying that the default value of the $\mathrm{BC}$ scavenging coefficient is set to $0 \%$. However, in order to assess the impact of $\mathrm{BC}$ scavenging we run a configuration implementing a $\mathrm{BC}$ scavenging coefficient of $20 \%$ according to the values provided in Flanner et al. (2007) and assessed by Doherty et al. (2013) and Yang et al. (2015). Yang et al. (2015) showed that dust particles are too large to be scavenged; consequently, the mineral dust scavenging coefficient was set to $0 \%$.

\subsection{Radiative transfer model in snow TARTES}

In the original version of Crocus, the albedo is computed for three large spectral bands only, accounting for the properties of the first two snow layers only (Brun et al., 1992; Vionnet et al., 2012). LAIs are not explicitly represented in the Crocus original version; their impact is implicitly taken into account by empirically decreasing snow albedo in the visible wavelengths as snow ages. 
In this study, the radiative impact of LAIs is explicitly computed using the Two-stream Analytical Radiative TransfEr in Snow (Libois et al., 2013) model, recently implemented in Crocus (Libois et al., 2015). This radiative transfer model computes the spectral absorption of solar radiation within the stratified snowpack using AART theory (Kokhanovsky and Zege, 2004) and the $\delta$-Eddington approximation (Jiménez-Aquino and Varela, 2005). TARTES makes use of four Crocus prognostic variables (SSA, density, snow layer thickness and impurity content) and of the angular and spectral characteristics of the incident radiance (solar zenith angle and spectrally resolved diffuse-to-total-irradiance ratio). LAIs are considered to be externally mixed to the snow and the computation of their radiative impact is based on the Rayleigh approximation (the size of the scattering particles is assumed to be much smaller than the wavelength). TARTES uses the ice refractive index and two additional variables to characterize each type of LAI: their density and their optical refractive index.

In the present study, we use the value of BC density from Flanner et al. (2012) $\left(1270 \mathrm{~kg} \mathrm{~m}^{-3}\right)$ and the value of mineral dust density from Hess et al. (1998) $\left(2600 \mathrm{~kg} \mathrm{~m}^{-3}\right)$. Concerning LAI refractive indexes, values of Chang and Charalampopoulos (1990) are used for BC, as in Libois et al. (2013). Two alternative parameterizations are tested for mineral dust because of the uncertainty of its optical properties. These two parameterizations were taken as an upper and a lower bound on the imaginary part of the refractive index of mineral dust found in the literature. Refractive index values from Müller et al. (2011) are taken as an upper bound of dust absorption and refractive index values from Skiles et al. (2014) are taken as a lower bound of dust absorption. For the ice refractive index we use the values of Warren and Brandt (2008).

\subsection{Atmospheric radiative transfer model ATMOTARTES}

TARTES requires as input the spectral direct-to-diffuse incoming irradiance ratio. In Crocus, it is computed using the newly developed ATMOTARTES scheme, a two-stream multilayer model for atmospheric radiative transfer based on the same two-stream code as TARTES (Libois et al., 2013).

The inputs of ATMOTARTES are the following atmospheric characteristics: surface pressure and temperature, surface relative humidity, solar zenith angle, day of year, aerosol optical depth at $0.55 \mu \mathrm{m}$, total ozone column (atm$\mathrm{cm}$ ), cloud bottom pressure, cloud type (ice or water) and cloud optical depth at $0.55 \mu \mathrm{m}$. The cloud optical thickness is diagnosed from the broadband diffuse and direct solar irradiance estimated from the Col de Porte measurements (see Dumont et al., 2017, for more details). The hourly ozone column and aerosol optical depth are provided by ALADIN-Climate. Surface pressure, temperature and relative humidity are provided by the meteorological forcings, and the solar zenith angle calculation is done within Crocus. In this study, the scheme is run with six layers in the clear sky case and with seven layers in the cloudy case (the cloud elevation is set to $8 \mathrm{~km})$.

The model is based on three main steps: (i) calculation of the atmospheric optical properties (optical depth, single-scattering albedo and asymmetry factor) for each atmospheric layer, (ii) $\delta$-Eddington approximation to account for the forward-scattering behavior of the atmospheric scatterer and (iii) two-stream calculation of the radiative flux. Steps (ii) and (iii) are identical to TARTES. For step (i) parameterization and lookup tables are taken from Justus and Paris (1985) and Ricchiazzi et al. (1998) to estimate top-ofatmosphere irradiance, aerosols and cloud optical properties. Rayleigh scattering is computed as in Nicolet (1984) and Bucholtz (1995). Uniformly mixed gas, ozone and water vapor absorptions are computed as in Bird and Riordan (1986). Ozone, water vapor and aerosol vertical profiles are typical midlatitude winter profiles from SBDART (Santa Barbara DISORT Atmospheric Radiative Transfer, Ricchiazzi et al., 1998). SBDART is a plane-parallel radiative transfer model for the atmosphere under clear and cloudy conditions. The solution of the radiative transfer equation is based on DISORT, so it is more sophisticated and time consuming than the two flux method used in ATMOTARTES. The model has been evaluated with respect to SBDART (Ricchiazzi et al., 1998) on 1260 different atmospheric profiles. It exhibits a satisfying overall agreement $\left(r^{2}>0.988\right)$.

\section{Data and methods}

\subsection{Data and study site}

The model simulations and evaluation were carried out at the Col de Porte experimental site for the 2013-2014 snow year. This site is located at $1325 \mathrm{~m}$ altitude in the Chartreuse Mountains, France. The model is forced with in situ meteorological measurements from the Col de Porte study site namely air temperature, specific humidity, rainfall and snowfall rates, incident direct and diffuse shortwave radiations, longwave incoming radiation and wind speed. An exhaustive description of the measurement devices and datasets can be found in Morin et al. (2012a). Hourly albedo at noon were calculated using spectral reflectance measurements described in Dumont et al. (2017). Measured spectral reflectance measurements were first converted to spectral reflectance for a flat surface using Eq. (8) in Dumont et al. (2017). Lastly the spectral reflectance values were integrated over the wavelength range of $350-2800 \mathrm{~nm}$, weighted by the incoming spectral irradiance, in order to provide broadband albedo. The same data have been used in Lafaysse et al. (2017) (Fig. 1). To constrain LAI deposition, we use aerosol deposition fluxes from the atmospheric model ALADIN-Climate, a regional climate model based on a bi-spectral semi-implicit semi-Lagrangian scheme (Bubnova et al., 1995). The ver- 
sion 5.3 (Nabat et al., 2015) is used in the present study with a $50 \mathrm{~km}$ horizontal resolution, 31 vertical levels and the ERA-Interim reanalysis (Dee et al., 2011) as lateral boundary forcing. For aerosols, no data are available at the lateral boundaries. Aerosol lateral boundary forcing is set to 0 because the ALADIN-Climate domain is considered to be large enough to include all the aerosol sources affecting the area. For instance, the domain includes the whole Saharan desert. ALADIN-Climate includes a prognostic aerosol scheme for the main aerosol species (dust, sea salt, sulfate, black carbon and organic matter), thus giving an interactive representation of their emission, transport and deposition. Only BC and mineral dust are considered in our snowpack simulations since they are the predominant species in terms of radiative impact in the Alps (Di Mauro et al., 2015). Wet deposition is only activated when there is measured precipitation.

During the 2013-2014 snow year, additional advanced measurements were carried out at the Col de Porte. First, chemical analyses of the top of the snowpack were realized on 11 February 2014. BC concentrations were measured with a single-particle soot photometer (SP2) after nebulization of the meltwater, and dust concentrations were measured with a Coulter counter giving vertical profiles from the top $27 \mathrm{~cm}$ of the snowpack with $3 \mathrm{~cm}$ resolution. Moreover spectral albedos were measured with an automatic spectroradiometer (Dumont et al., 2017) during the season. The automatic spectroradiometer used was an Autosolexs instrument, whose full description can be found in Picard et al. (2016b).

\subsection{Spectral albedo processing}

These automatic spectral albedos were processed in order to compute near-surface impurity concentrations and specific surface area by Dumont et al. (2017). These data are compared to near-surface properties of snow simulated by the model in the present study. The model evaluation was performed using the algorithm described in Dumont et al. (2017) applied to Crocus spectral albedo predictions. It accounts for the impact of the top centimeters of the snowpack on spectral albedo, and not only for the Crocus top layer (which is sometimes thinner than the optical $e$-folding depth). In other words, instead of directly using LAI content and SSA from the Crocus top layer, the simulated spectral albedo was used to compute an effective value for near-surface SSA and equivalent $\mathrm{BC}$ content. The equivalent $\mathrm{BC}$ content is the concentration of $\mathrm{BC}$ in the snow uppermost layers that would have a similar effect on snow spectral albedo that all types of LAIs taken together. Near-surface LAI content and SSA are generally not available during snowfall due to large uncertainties in albedo measurements (Dumont et al., 2017).

\subsection{Model setup}

In this study, all physical options of the Crocus model are set to the default ones as defined in Lafaysse et al. (2017), with the exception of turbulent surface fluxes and surface heat capacity (options RI2 and CV50000). This includes option C13 of the metamorphism scheme implemented by Carmagnola et al. (2014) with prognostic SSA. Hereafter, we refer to the Crocus version using these particular settings as our reference version.

To evaluate the new developments in Crocus we ran different simulations described in Table 1 . The the $\mathrm{C} 0$ configuration corresponds to the reference version of Crocus described above. This configuration does not use the spectral radiative transfer model TARTES, but the original parameterization of solar radiation absorption implemented by Brun et al. (1992). The the $\mathrm{C} 1$ configuration uses the snow radiative transfer model TARTES without impurities while configurations $\mathrm{C} 2, \mathrm{C} 3, \mathrm{C} 4$ and $\mathrm{C} 5$ use TARTES with the new developments. The the $\mathrm{C} 2$ configuration uses dust refractive index values from Müller et al. (2011) and no scavenging at all. The C3 configuration uses dust refractive index values from Skiles et al. (2014) and no scavenging at all. The C4 configuration uses our new developments with dust refractive index values from Müller et al. (2011) and the scavenging coefficient is set to $20 \%$ for $\mathrm{BC}$. Configurations $\mathrm{C} 2, \mathrm{C} 3$ and $\mathrm{C} 4$ use $\mathrm{BC}$ and dust deposition fluxes from the atmospheric model ALADIN-Climate (more details in Sect. 3.1).

During the 2013-2014 snow season, two major dust outbreaks occurred in the Alps. Those events are of particular interest for our study as they bring large amount of LAIs at once in the snowpack. First, in mid-February a major dry deposition event struck the Alps. On 16 February a significant wet deposition occurred. Then, on 19 February an intense dry deposition followed, leading to a visually observable reddish layer highly concentrated in dust. Secondly, on 3 April another major dry deposition event affected the Alps, followed by a significant wet deposition event on 6 April.

The C5 configuration uses the same parameterization as $\mathrm{C} 2$ but the ALADIN-Climate deposition fluxes were adjusted as follows. For the first dust event, deposition fluxes have been adjusted to match measured dust concentrations at the surface. Indeed, for this outbreak Di Mauro et al. (2015) measured dust concentration ranging from 50 to $330 \mu \mathrm{g} \mathrm{g}^{-1}$ in the Italian Alps, in a site located approximately $200 \mathrm{~km}$ east of the Col de Porte at a similar elevation of $1650 \mathrm{~m}$. As dust outbreaks are large-scale events, we made the coarse assumption that dust concentrations for this dust outbreak are similar for these two places. For the second major dust outbreak we have not found any measurements, so we assumed it had the same magnitude as the first one. We consequently multiplied the dry deposition coefficient by 25 on 19 February and on 3 April for the two major outbreaks and the wet deposition coefficient by 10 on 6 April to compute a similar deposition. We obtain a deposited near-surface dust concentration of roughly $200 \mu \mathrm{g} \mathrm{g}^{-1}$ for each event (from 90 to $300 \mu \mathrm{g} \mathrm{g}^{-1}$ for the first

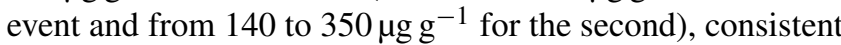
with the range of values proposed by Di Mauro et al. (2015). Except for these 3 days, the deposition fluxes have not been 
Table 1. Crocus configurations used.

\begin{tabular}{|c|c|c|c|c|c|}
\hline & \multirow[b]{2}{*}{ Settings } & \multicolumn{2}{|r|}{$\mathrm{BC}$} & \multicolumn{2}{|r|}{ Dust } \\
\hline & & Scavenging & Optical properties & Scavenging & Optical properties \\
\hline $\mathrm{CO}$ & Reference version & - & - & - & - \\
\hline $\mathrm{C} 1$ & TARTES without impurities & - & - & - & - \\
\hline $\mathrm{C} 2$ & $\begin{array}{l}\text { TARTES with ALADIN-Climate } \\
\text { deposition fluxes }\end{array}$ & $0 \%$ & Chang and Charalampopoulos (1990) & $0 \%$ & Müller et al. (2011) \\
\hline $\mathrm{C} 3$ & $\begin{array}{l}\text { TARTES with ALADIN-Climate } \\
\text { deposition fluxes }\end{array}$ & $0 \%$ & Chang and Charalampopoulos (1990) & $0 \%$ & Skiles et al. (2014) \\
\hline $\mathrm{C} 4$ & $\begin{array}{l}\text { TARTES with ALADIN-Climate } \\
\text { deposition fluxes }\end{array}$ & $20 \%$ & Chang and Charalampopoulos (1990) & $0 \%$ & Müller et al. (2011) \\
\hline C5 & $\begin{array}{l}\text { TARTES with ALADIN-Climate modified } \\
\text { deposition fluxes } \\
\text { (accounting for dust outbreaks) }\end{array}$ & $0 \%$ & Chang and Charalampopoulos (1990) & $0 \%$ & Müller et al. (2011) \\
\hline
\end{tabular}

modified. The C5 simulation has been run in order to understand the discrepancies between simulated and measured surface impurity concentrations.

Finally soil temperatures have been initialized by running a single 10-year spin-up, with the C0 configuration, from 2003 to 2013 using in situ meteorological data.

\subsection{Broadband albedo computation}

Lafaysse et al. (2017) have shown that Crocus broadband shortwave albedo features a large bias (up to 0.1 depending on the configuration) compared to the Col de Porte albedo measurements described in Morin et al. (2012a). In order to investigate the origin of this bias we run an additional computation with an offline version of the TARTES radiative transfer model. This run uses impurity content simulated with C5 and SSA values retrieved from spectral albedo measurements from Dumont et al. (2017). This simulation is only used in the Section 4.4 and is referred to as "C5(SSA)".

Similar to the measurements, we only consider broadband albedo computed at noon from downwelling and upwelling broadband radiation fluxes simulated by Crocus. For the $\mathrm{C} 0$ configuration we use broadband downwelling and upwelling shortwave fluxes at noon to compute the albedo. For the other configurations, we integrate the spectral downwelling and upwelling shortwave fluxes on the shortwave range (300$2800 \mathrm{~nm}$ ) to compute the broadband albedo. Measured and simulated broadband albedo are then compared for days when the simulated snow depth is higher than 0 in all of our simulations and automated spectral albedo measurements are available (46 days in total).

\subsection{Estimation of direct and indirect impacts}

Estimating the portion of LAI radiative forcing due to the indirect impact requires the separation of LAI evolution and microstructure evolution. With this aim in mind, an additional computation called $\mathrm{C} 2$ ind was performed, using an offline version of TARTES. This computation provides snow- pack energy absorption using SSA values from C2 simulation while LAI concentrations are set to 0 . In this way, energy absorption due to LAI in $\mathrm{C} 2$ ind only accounts for the accelerated metamorphism disregarding snow darkening (direct impact).

By comparing $\mathrm{C} 2$ ind computation to $\mathrm{C} 1$ (pure snow) and to C2 (full impact of LAIs), we are able to quantify the relative importance of the indirect radiative forcing of LAIs on snow, $R_{\text {ind }}$, thanks to the ratio

$R_{\text {ind }}=\frac{E_{\mathrm{C} 2}-E_{\mathrm{C} 2 \text {,ind }}}{E_{\mathrm{C} 2}-E_{\mathrm{C} 1}}$,

with $E_{X}$ being the energy absorbed by the snowpack in configuration $\mathrm{X}$. This ratio can be determined daily, $R_{\text {ind,daily }}$, or over the whole season, $R_{\text {ind,season }}$, by applying Eq. (5) to the cumulative absorbed energy. Note that the same method can be applied by replacing $\mathrm{C} 2$ with $\mathrm{C} 3, \mathrm{C} 4$ or $\mathrm{C} 5$.

Our method to compute the LAIs' indirect impact is based on the assumption that the total energy absorbed by the snowpack is the sum of the energy absorbed by clean snow and of the LAI impact (direct and indirect). If the ground plays an important role in total energy absorption, our method cannot be applied because the influence of the ground may differ between $\mathrm{C} 1$ and $\mathrm{C} 2$ and cause differences in energy absorption unrelated to LAIs. For this reason all dates with SWE values lower than $50 \mathrm{~kg} \mathrm{~m}^{-2}$ are discarded. This threshold value was obtained by a sensitivity analysis of ground impact on snow visible albedo adapted to our simulations. For clean snow with high SSA $\left(>20 \mathrm{~m}^{2} \mathrm{~kg}^{-1}\right)$, an SWE value of $50 \mathrm{~kg} \mathrm{~m}^{-3}$ is sufficient to ensure that ground impact is lower than $2 \%$, but for clean snow with low SSA $\left(5 \mathrm{~m}^{2} \mathrm{~kg}^{-1}\right)$ it would be insufficient (the impact of the ground reduces visible albedo up to $6 \%$ ). However, in our simulation, at the end of the season the surface snow contains at least $100 \mathrm{ng} \mathrm{g}^{-1}$ of BC equivalent, reducing the optical $e$-folding depth enough to guarantee that the ground does not influence the total energy absorption more than $2 \%$ if the SWE is higher than $50 \mathrm{~kg} \mathrm{~m}^{-2}$ (even with SSA of $5 \mathrm{~m}^{2} \mathrm{~kg}^{-1}$ ). 

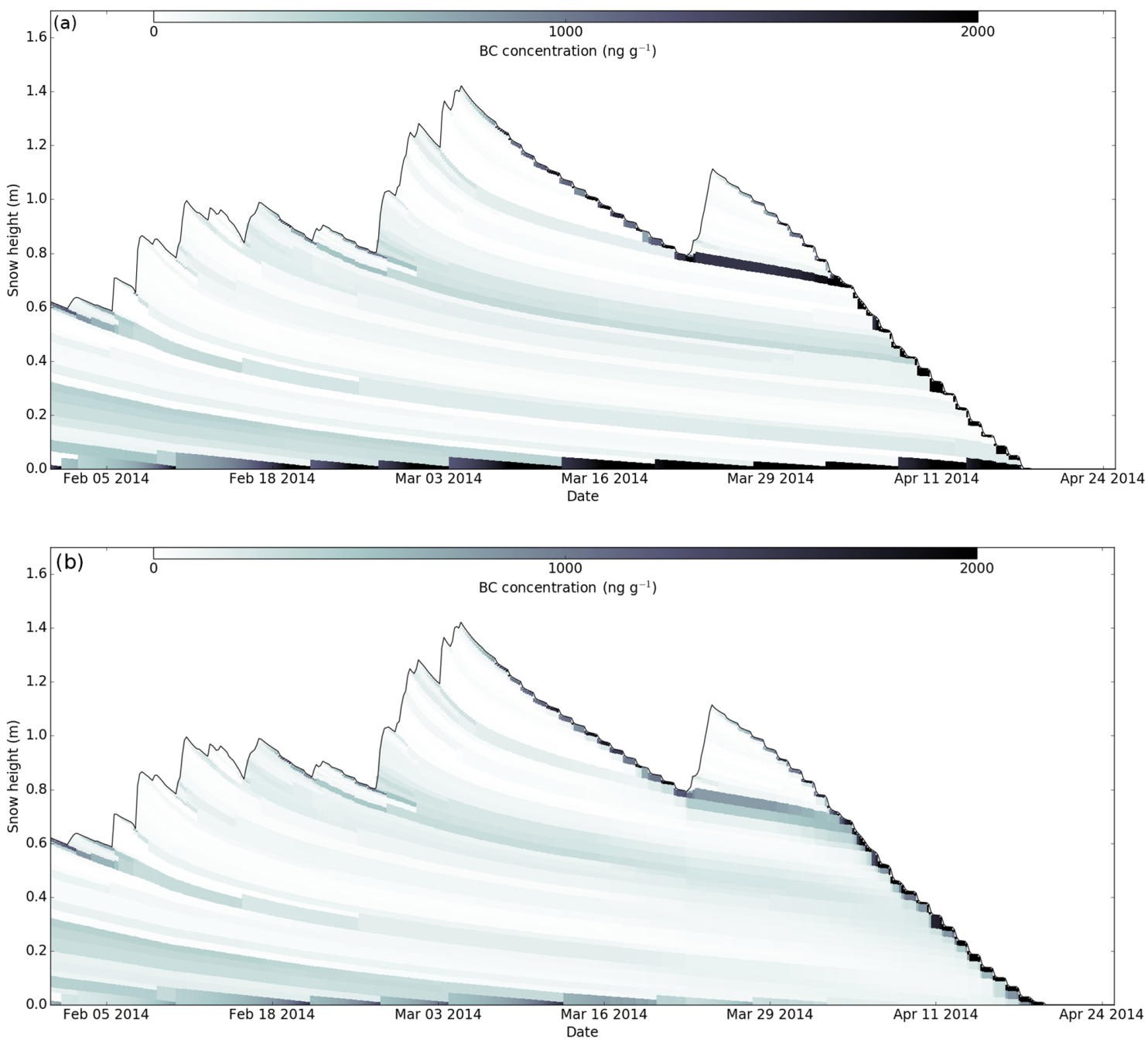

Figure 2. Simulated BC concentration evolution at the end of the 2013-2014 snow season at the Col de Porte. (a) corresponds to a simulation without scavenging, whereas (b) corresponds to a simulation using the value of $20 \%$ for $\mathrm{BC}$ scavenging.

\section{Results}

\subsection{Impact of scavenging on the simulated $\mathrm{BC}$ vertical profiles}

Figure 2 shows the evolution of $\mathrm{BC}$ concentration for simulations $\mathrm{C} 2$ and $\mathrm{C} 4$ during the second half of the season. The differences between these two simulations are only due to the value of the $\mathrm{BC}$ scavenging coefficient, set to 0 for $\mathrm{C} 2$ and $20 \%$ for $\mathrm{C} 4$. The $\mathrm{BC}$ concentration is almost identical in both cases at the beginning of the period considered, when melt does not occur yet. Then, when melting starts, scavenging decreases $\mathrm{BC}$ surface concentration and transfers a part of the $\mathrm{BC}$ content to the soil at the bottom of the snowpack (Fig. 2b). We can also observe that scavenging transfers a mass of $\mathrm{BC}$ from the bottom of the snowpack to the ground throughout the season due to basal melt.

\subsection{Bulk snowpack variables}

Figure 3 shows snow depth (upper panel) and snow water equivalent (lower panel) measured and simulated in the different configurations. Both automatic and manual measurements are shown (represented in black) to illustrate the spatial variability of these variables within the measurement field area because they are not collected at the exact same place.

Snow depth is underestimated by roughly $20 \mathrm{~cm}$ compared to automatic measurements for all configurations at the beginning of the season, from the first snowfall to 24 December. Once this initial snowpack has melted, there is a better agreement between observed and simulated snow depth values with all the configurations. The second column of Table 2 presents the RMSE between each simulation and the automatically measured snow depth time series. Over the whole season, the maximum RMSE is $10.0 \mathrm{~cm}(\mathrm{C} 1)$. The third col- 
Table 2. RMSE and bias between measured and simulated variables. For snow depth and SWE, the RMSE and bias are computed from the automatic measurements. The SSA values are computed from the spectral albedo both measured and simulated. The spectral albedo computation is not activated in the reference Crocus version ( $\mathrm{C} 0$ ), explaining the lack of RMSE and bias values for the corresponding box.

\begin{tabular}{lrr|rrr}
\hline Configuration & \multicolumn{2}{c|}{ Depth } & SWE & $\begin{array}{r}\text { Near-surface } \\
\text { SSA }\end{array}$ & $\begin{array}{r}\text { Broadband shortwave } \\
\text { albedo at noon }\end{array}$ \\
\hline & $\begin{array}{r}\text { RMSE(bias) } \\
\text { from 05/11/13 } \\
\text { to 01/05/14 }\end{array}$ & $\begin{array}{r}\text { RMSE(bias) } \\
\text { from 26/12/13 } \\
\text { to 01/05/14 }\end{array}$ & $\begin{array}{r}\text { RMSE(bias) } \\
\text { from 05/11/13 } \\
\text { to 01/05/14 }\end{array}$ & $\begin{array}{r}\text { RMSE(bias) } \\
\text { from 15/02/13 } \\
\text { to 15/04/14 }\end{array}$ & $\begin{array}{r}\text { RMSE(bias) } \\
\text { from 15/02/13 } \\
\text { to 15/04/14 }\end{array}$ \\
\hline C0 & $8.5(-6.9) \mathrm{cm}$ & $6.4(-5.3) \mathrm{cm}$ & $90.2(-79.1) \mathrm{kg} \mathrm{m}^{-2}$ & & - \\
C1 & $10.0(-2.7) \mathrm{cm}$ & $8.0(+1.2) \mathrm{cm}$ & $71.6(-64.2) \mathrm{kg} \mathrm{m}^{-2}$ & $7.6(+4.9) \mathrm{m}^{2} \mathrm{~kg}^{-1}$ & $0.059(+0.049)$ \\
C2 & $8.9(-6.1) \mathrm{cm}$ & $6.0(-3.8) \mathrm{cm}$ & $84.4(-75.0) \mathrm{kg} \mathrm{m}^{-2}$ & $6.9(+4.2) \mathrm{m}^{2} \mathrm{~kg}^{-1}$ & $0.121(+0.094)$ \\
C3 & $8.8(-5.9) \mathrm{cm}$ & $5.8(-3.4) \mathrm{cm}$ & $82.9(-74.0) \mathrm{kg} \mathrm{m}^{-2}$ & $6.9(+4.1) \mathrm{m}^{2} \mathrm{~kg}^{-1}$ & $0.078(+0.060)$ \\
C4 & $8.8(-5.9) \mathrm{cm}$ & $5.9(-3.5) \mathrm{cm}$ & $83.4(-74.3) \mathrm{kg} \mathrm{m}^{-2}$ & $6.9(+4.2) \mathrm{m}^{2} \mathrm{~kg}^{-1}$ & $0.081(+0.063)$ \\
C5 & $9.0(-6.4) \mathrm{cm}$ & $6.2(-4.1) \mathrm{cm}$ & $85.6(-75.8) \mathrm{kg} \mathrm{m}^{-2}$ & $6.9(+4.3) \mathrm{m}^{2} \mathrm{~kg}^{-1}$ & $0.067(+0.054)$ \\
C5(SSA) & - & - & - & & - \\
\hline
\end{tabular}
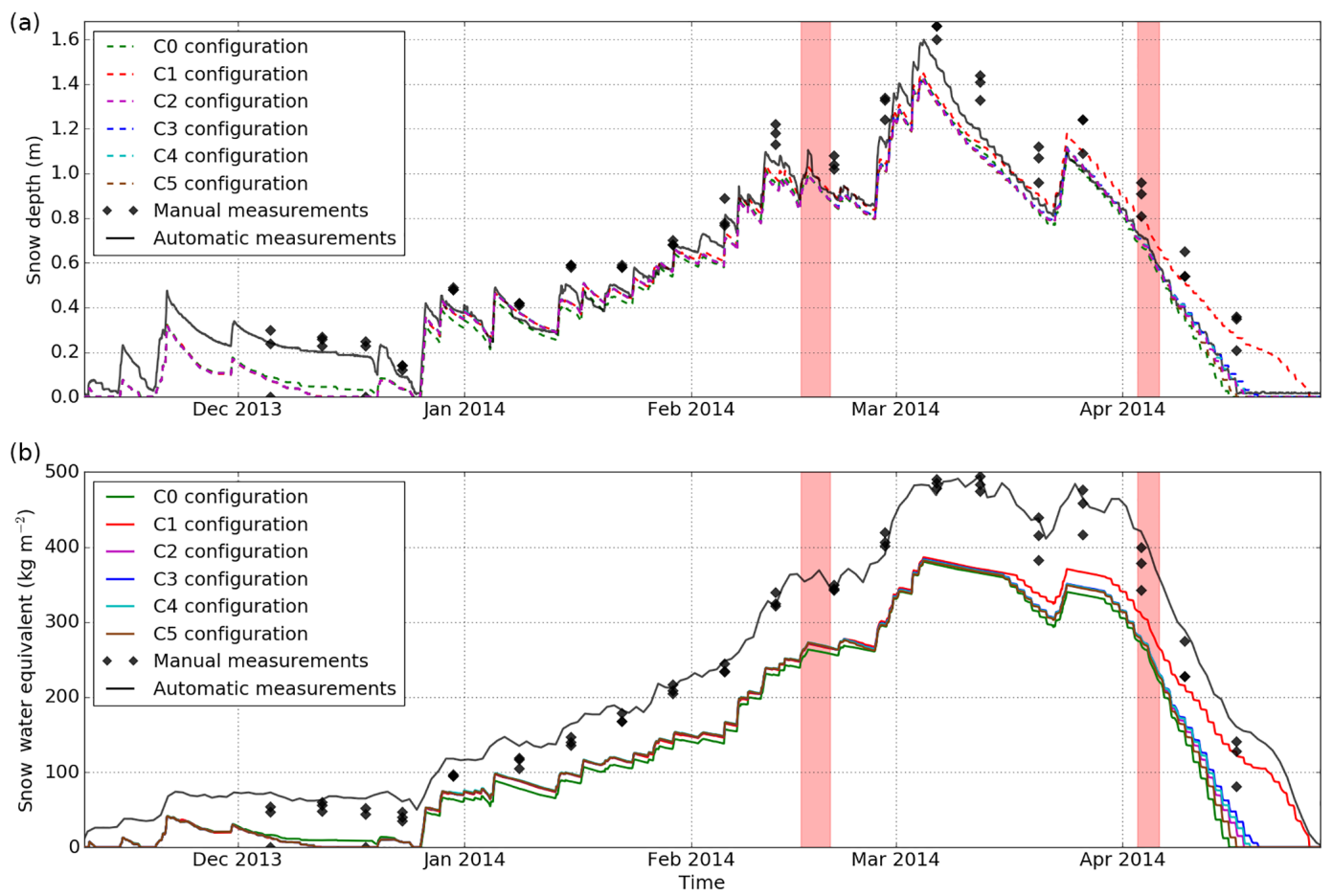

Figure 3. Measured and simulated total snow depth (a) and total SWE (b) at the Col de Porte along the 2013-2014 snow year. The two major Saharan dust events are represented by the red shading.

umn of Table 2 also presents the RMSE from 26 December to the melt-out date of the snowpack to better quantify the impact of the configuration on total snow depth estimates disregarding the bias at the beginning of the season. Over this period, the maximum RMSE is $8.0 \mathrm{~cm}(\mathrm{C} 1)$. It should be noted that $\mathrm{C} 1$ has also the smallest bias because the underestimation of snow depth during the season (similar to all the other configurations) is compensated by a large overestimation of snow depth from May 20 onward. The values of snow depth bias and RMSE in the present study are consis- tent with the range of values found for an 18-year period with the recent model uncertainty analysis described in Lafaysse et al. (2017). This value has the same magnitude as the uncertainty of the reference snow depth as quantified in Lafaysse et al. (2017), as a consequence of spatial variability. Lafaysse et al. (2017) showed that the automatic snow depth measurements tend to be lower by $9 \mathrm{~cm}$ compared to the average of manual snow depth measurements at the Col de Porte. 
We can also notice that the melt-out date of the snowpack advances by 6 to 9 days when accounting for radiative impact of impurities in snow (comparing C2, C3 and C4 with C1).

Regarding SWE, there is an underestimation in the model during all the snow season compared to both manual and automatic measurements. SWE estimates over the season are similar for all configurations until melt time, when LAIs modify the melting rate. The RMSE between measured and simulated SWE is $90.2 \mathrm{~kg} \mathrm{~m}^{-2}$ for $\mathrm{C} 0$ and around $80.0 \mathrm{~kg} \mathrm{~m}^{-2}$ for the other configurations. The minimum RMSE $\left(71.6 \mathrm{~kg} \mathrm{~m}^{-2}\right)$ and bias $\left(64.2 \mathrm{~kg} \mathrm{~m}^{-2}\right)$ are obtained for the $\mathrm{C} 1$ configuration. There is a significant bias (around $70 \mathrm{~kg} \mathrm{~m}^{-2}$ ), which is higher than the magnitude of the reference SWE uncertainty quantified by Lafaysse et al. (2017). However, during this specific season, the automatic snow depth measurements indicate $0 \mathrm{~cm}$ of snow on 26 December whereas the SWE automatic measurements indicates more than $70 \mathrm{~kg} \mathrm{~m}^{-2}$ (Fig. 3). These results are consistent with the Lafaysse et al. (2017) study, which pointed out that spatial variability within the Col de Porte site can strongly affect the results of the measurements (about $10 \%$ ). It shows that automatic SWE measurements at the Col de Porte tend to be higher by $15 \mathrm{~kg} \mathrm{~m}^{-2}$ compared to the average of manual SWE measurements. This process can at least partially explain the relatively low bias obtained for snow depth and the large bias in SWE. A season-specific bias of bulk density is also possible, although no long-term bias of this variable was identified by Lafaysse et al. (2017).

\subsection{Near-surface properties}

Figure 4 shows the near-surface impurity concentrations (upper panel) and SSA (lower panel) computed from measured and simulated spectral albedo from 15 February to snow melt-out (around mid-April for all the configurations) by the method described in Sect. 3.2. These values are computed from processed spectral albedo, and C0 (without spectrally resolved albedo) is consequently excluded from the analysis.

The simulated surface impurity content remains within the uncertainties of the indirectly measured data (error bars in the upper panel of Fig. 4) except at the very end of the season from approximately 5 April. After this date, the impurity content is lower in Crocus than in the observations. The upper panel of Fig. 4 offers an insight into the impact of the parameters modified in the different configurations. The difference between configurations $\mathrm{C} 2$ and $\mathrm{C} 4$ becomes significant at the very end of the season when strong melting occurs. Before melt time, scavenging does not affect near-surface impurity concentration (Fig. 2): $\mathrm{C} 2$ and $\mathrm{C} 4$ runs give similar results. The difference between $\mathrm{C} 2$ and $\mathrm{C} 3$ simulations is caused by the different absorption parameterization used for mineral dust. In the $\mathrm{C} 3$ configuration, dust absorbs less than in $\mathrm{C} 2$. The equivalent $\mathrm{BC}$ concentration needed to reproduce an equivalent impact on snow albedo is thus lower for $\mathrm{C} 3$ when dust is present. In turn, the dates for which C2 and C3 are similar correspond to situations when mineral dust is not the dominant absorber.

The Crocus near-surface SSA decreases too slowly after a snowfall under the Col de Porte meteorological conditions, regardless of the configuration (Fig. 4, lower panel). The decrease rate of SSA is computed using the C13 metamorphism scheme implemented by Carmagnola et al. (2014), which has not been modified in this study. However, it is clear that the impact of LAI modifies the SSA decrease rate. Indeed with the $\mathrm{C} 1$ configuration the bias between measured and simulated near-surface SSA is $-4.9 \mathrm{~m}^{2} \mathrm{~kg}^{-1}$ against $-4.2 \mathrm{~m}^{2} \mathrm{~kg}^{-1}$ for the configurations implementing LAIs. Figure 4 highlights that SSA values for C2, C3 and $\mathrm{C} 4$ are almost the same, indicating that the different LAI parameterizations used in this study have a negligible impact on surface SSA evolution.

\subsection{Broadband shortwave albedo}

Figure 5 shows the evolution of the simulated and measured broadband albedo at noon. The simulated broadband albedo is higher than the measurements for all the configurations except for C5(SSA), for which SSA values have been adjusted to measured ones.

The last column of Table 2 provides the albedo bias and RMSE resulting from this comparison. Those results are consistent with RMSE and bias values obtained in the Lafaysse 2017 ensemble simulation. Except for C5(SSA), $\mathrm{C} 0$ outperforms the other configurations in terms of albedo. Equivalent scores are obtained for the $\mathrm{C} 5$ configuration, and the difference between $\mathrm{C} 1$ and $\mathrm{C} 2, \mathrm{C} 3$ and $\mathrm{C} 4$ shows that accounting for LAIs largely improves the albedo simulations over a simulation neglecting the impact of impurities. Albedo bias for C5 simulation is significantly reduced by using measured SSA values instead of the simulated ones, suggesting that the albedo bias is partly explained by the bias in SSA.

\subsection{Profiles of impurity concentration}

Figure 6 shows vertical profiles of $\mathrm{BC}$ and dust content in the top $25 \mathrm{~cm}$ of the snowpack on 11 February, both measured and simulated with configurations $\mathrm{C} 2$ to $\mathrm{C} 4$. BC concentrations are significantly overestimated and dust contents are underestimated. Moreover, the vertical structure is not correctly reproduced. It should be noted that, in our simulation, the uppermost $17 \mathrm{~cm}$ of snow corresponds to a unique snowfall that occurred on 10 February. During this snowfall ALADIN-Climate did not simulate any mineral dust deposition explaining the absence of dust in this part of the snowpack.

\subsection{Quantification of direct and indirect LAI radiative impact}

The upper panel of Fig. 7 shows the energy absorbed by the snowpack for $\mathrm{C} 1, \mathrm{C} 2$ and $\mathrm{C} 2$ ind; the grey shaded ar- 


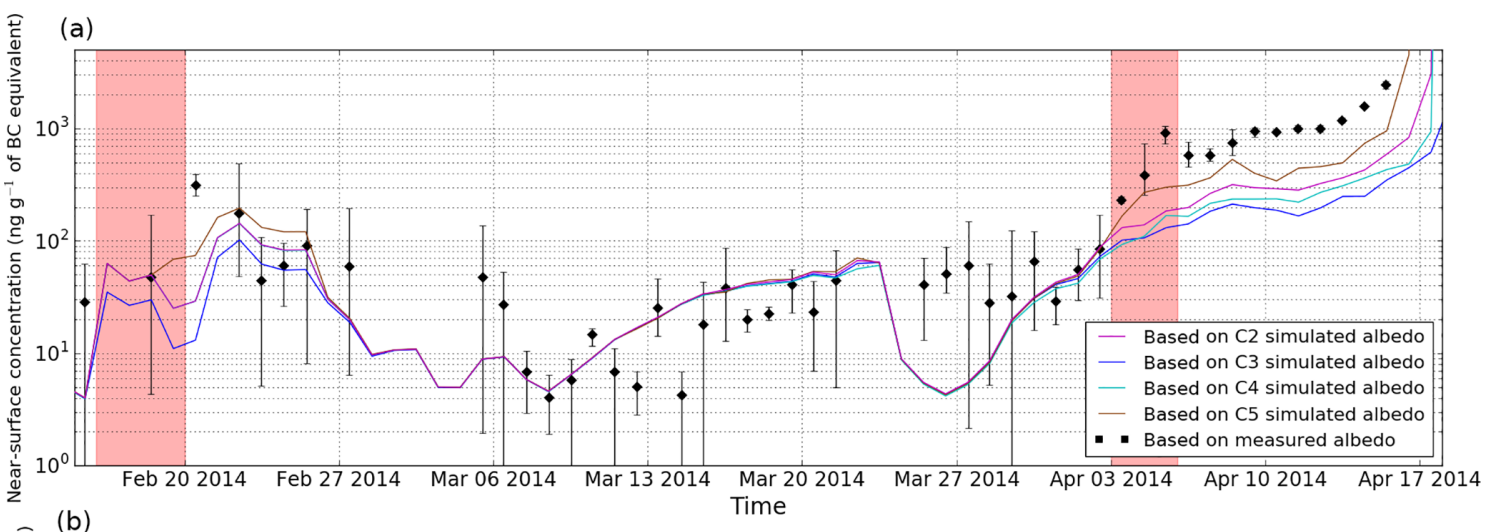

(b)

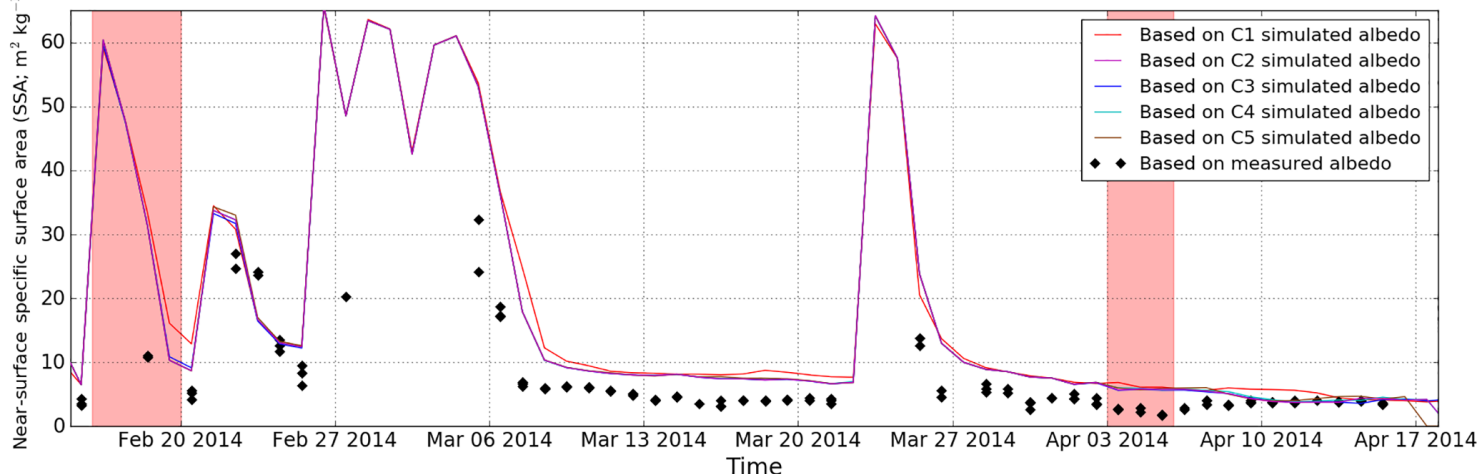

Figure 4. Surface BC equivalent concentration (a) and SSA (b) computed from measured and simulated albedo. For simulated albedo, the different Crocus configurations are detailed in Table 1. These data have been computed using the Dumont et al. (2017) algorithm, and the two major Saharan dust events are represented by the red areas.

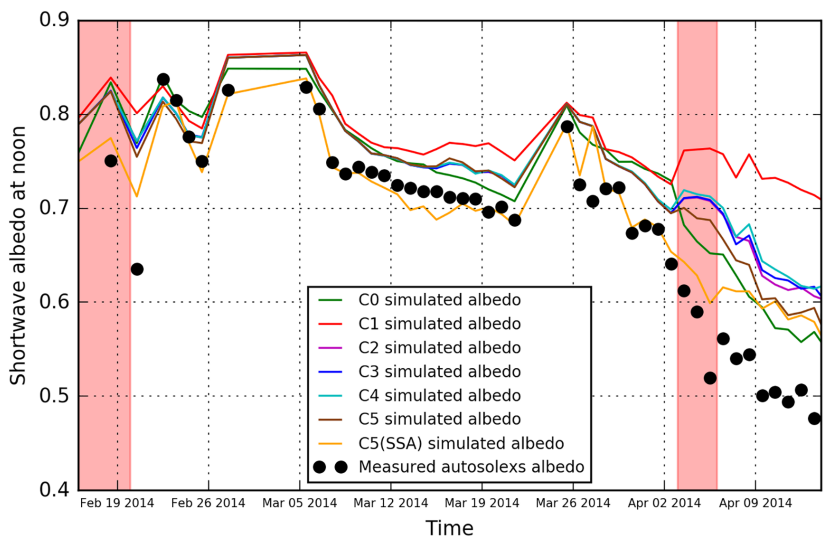

Figure 5. Shortwave broadband albedo at noon. The colored lines correspond to simulated albedo while the black dots correspond to Autosolexs-measured albedo (Dumont et al., 2017). The two major Saharan dust events are represented by the red shading.

eas indicates the period during which SWE is less than $50 \mathrm{~kg} \mathrm{~m}^{-1}$ in both simulations. The daily energy absorption (full lines) shows that the total radiative impact of LAIs increases through the season (difference between the red and the green curves). Applying Eq. (5) on the cumulative energy absorbed during the season (dashed lines) provides the ratio of LAI radiative impact due to the indirect impact over

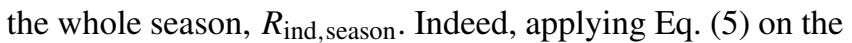
total cumulative energy absorbed at the end of the study period, we determine that over the season $15.3 \%$ of LAI radiative forcing is due to the indirect impact $\left(R_{\text {ind, season }}\right)$, while $84.7 \%$ of the LAI impact is caused by the direct impact. The lower panel in Fig. 7 shows the daily percentage of LAI radiative forcing caused by the indirect impact along the snow season. The values potentially affected by the ground (in orange) have to be taken with caution because the ground influence might have modified the results. These results are shown in parallel to the value of the SSA because the indirect impact of LAIs is due to an acceleration of snow metamorphism, indicating an acceleration in the SSA decrease rate.

Section 4.2 and 4.4 highlight that C5 provides better results than $\mathrm{C} 2$ in terms of near-surface LAI concentration and shortwave albedo. Given that radiative forcing is expected to be more accurate for $\mathrm{C} 5$, the same method has also been applied using $\mathrm{C} 5$ as a control run (instead of $\mathrm{C} 2$ in Fig. 7). We obtain similar results in terms of temporal evolution but the distribution between the average direct and indirect impacts is only slightly modified, with $14.1 \%$ attributed to the indirect impact instead of $15.3 \%$, which we consider an insignificant variation. 

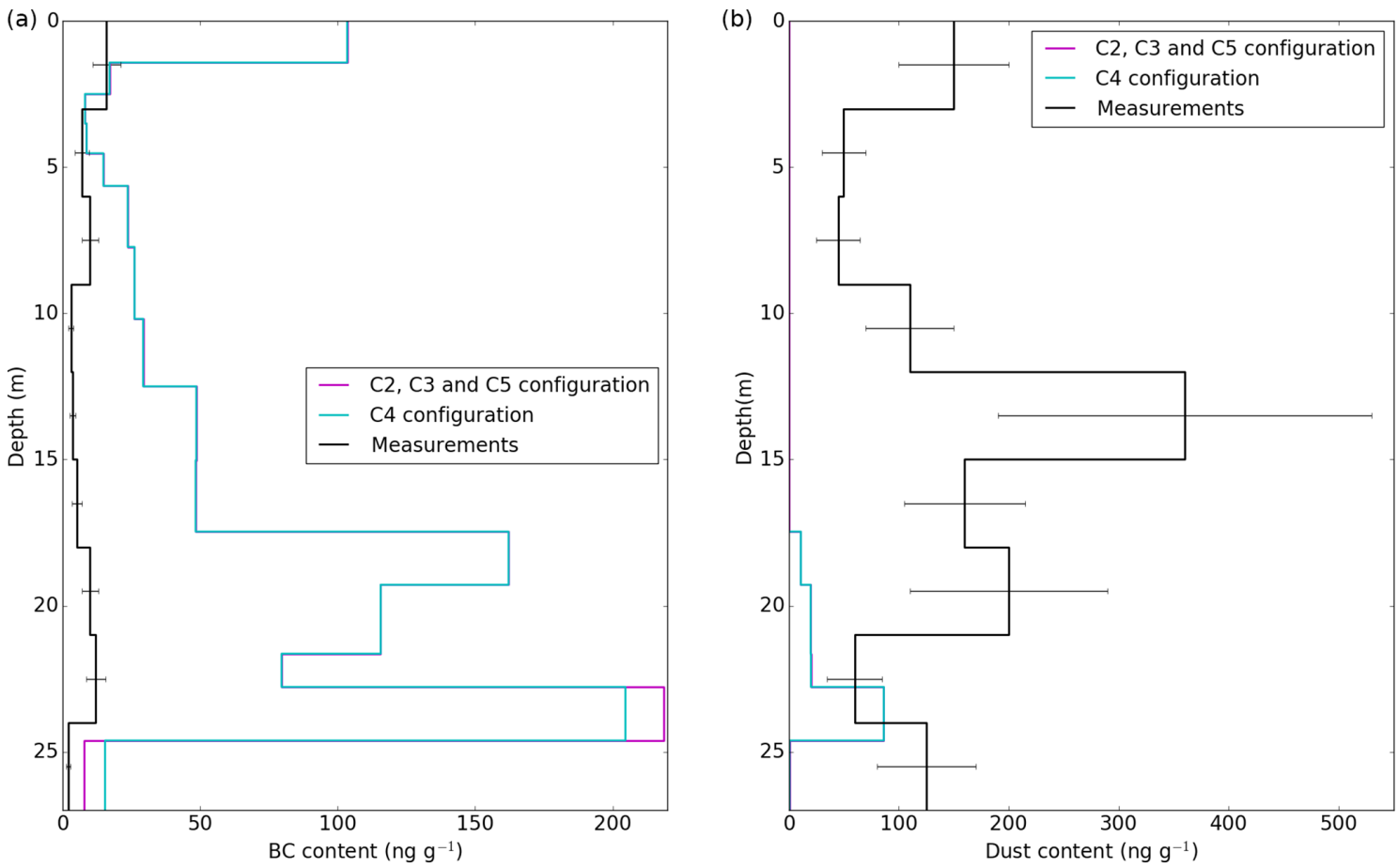

Figure 6. BC (a) and dust (b) concentrations at the Col de Porte on 11 February 2014.
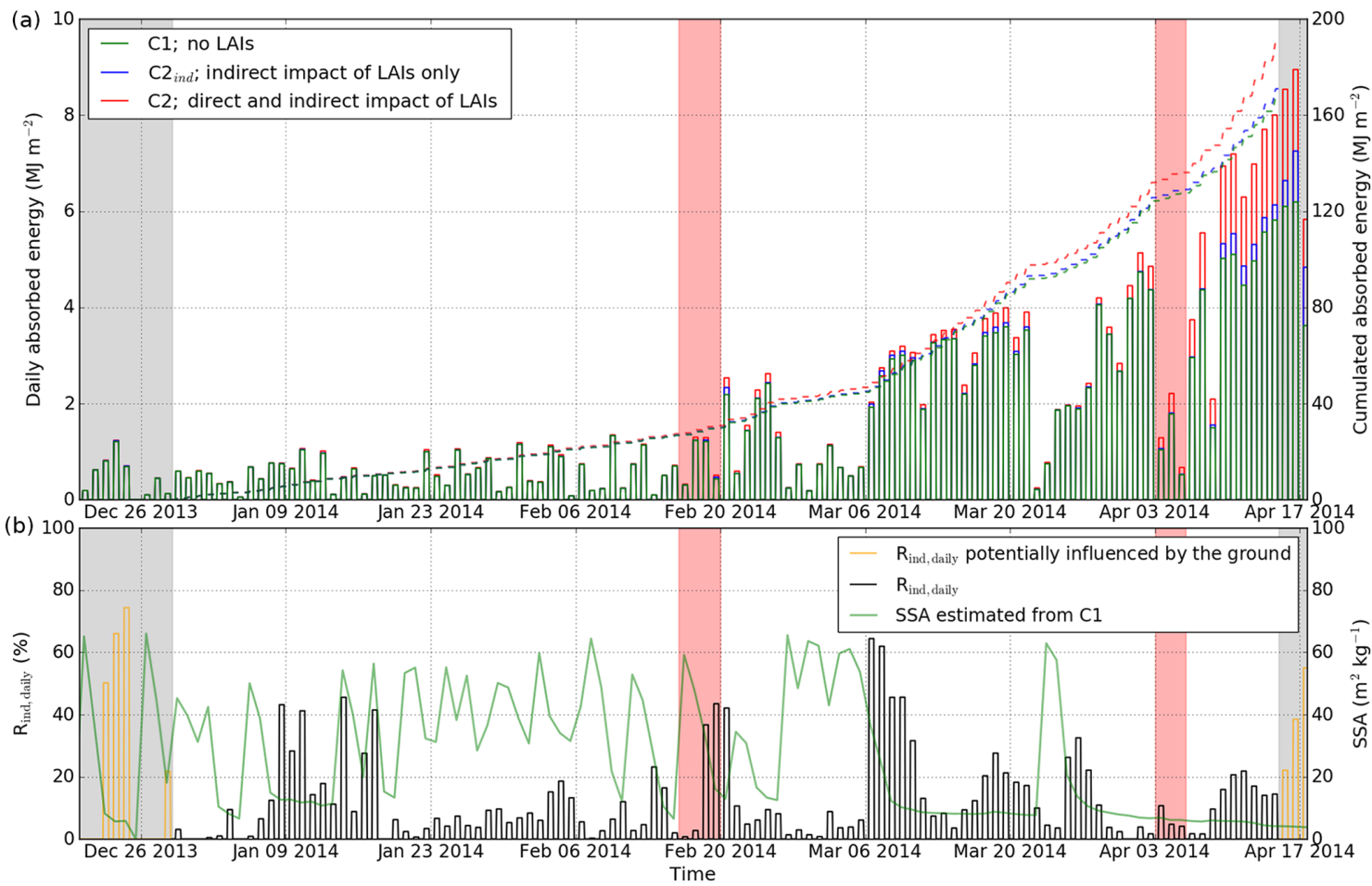

Figure 7. Energy absorbed by the snowpack during the season (a); the full lines correspond to the daily amount of energy absorbed whereas the dashed lines correspond to the cumulative energy absorbed over the study period. $R_{\text {ind,daily }}$ compared to near-surface SSA computed from C1 (b); $R_{\text {ind,daily }}$ is the daily relative importance of LAIs in snow radiative forcing coming from the indirect impact (Eq. 5 applied to daily energy absorption). The dates during which the ground influences the energy budget have been masked (grey shading). The red shading represents two major Saharan dust events. 


\section{Discussion}

\subsection{Simulated LAI contents}

Section 4.5 highlighted discrepancies between simulated and measured dust and BC vertical profiles for 11 February 2014. The $\mathrm{BC}$ content simulated by the model is an order of magnitude higher than the measured $\mathrm{BC}$ content. In contrast the dust content simulated by the model is an order of magnitude lower than the measured dust content. For both types of LAIs the vertical structure is not reproduced. Several hypotheses can explain these discrepancies.

First, ALADIN-Climate has a $50 \mathrm{~km}$ horizontal resolution which cannot represent the local orography around the Col de Porte site. Hence, the atmospheric variables in the model (e.g., wind, precipitation rate) do not account for small-scale topography which is particularly important in mountain areas. For example, in ALADIN-Climate local dust erosion is represented as a function of wind and soil characteristics. If the wind on the grid point is low but small-scale phenomena induce stronger winds near the Col de Porte, the resulting soil erosion and transport are not caught by ALADIN-Climate. This last point can explain partly or totally the strong underestimation of mineral dust concentration in the model.

Secondly, the Col de Porte experimental site is located near Grenoble, France, which is a city affected by high levels of air contamination (Maître et al., 2002). However, the Col de Porte is more than $1000 \mathrm{~m}$ higher in elevation than Grenoble. The difference between simulated and measured $\mathrm{BC}$ concentration vertical profiles may come from an overestimation of Grenoble's impact on the Col de Porte study site by ALADIN-Climate. The deposition fluxes extracted from ALADIN-Climate correspond to a grid cell associated with an elevation of $523 \mathrm{~m}$ and an altitude difference of about $800 \mathrm{~m}$. Even if this cell does not include Grenoble, it may explain partially the overestimation of $\mathrm{BC}$ deposition by the model. Moreover persistent winter inversions are frequently observed in Grenoble. These phenomena could lead to accumulation of $\mathrm{BC}$ emissions in the lower part of the atmosphere, preventing significant transport to the Col de Porte. ALADIN-Climate cannot represent these winter inversions because of their relative small scale compared to the model resolution. This may also partly explain the overestimation of BC deposition fluxes predicted by the model.

Even though the vertical impurity concentration profiles on 11 February, presented above, are not correctly simulated, the near-surface $\mathrm{BC}$ equivalent computed from simulations is in good agreement with the one computed from measured spectral albedo except at the end of the season (from 5 April). The main cause of the divergence at the end of the season might be an underestimation of the two major Saharan dust outbreaks by ALADIN-Climate. The chronology of major dust outbreaks for snow year 2013-2014 is presented in Sect. 3.3 (see Fig. 8).
A plausible assumption is that the amount of dust deposited by each of these two major dust outbreaks at the Col de Porte are underestimated by ALADIN-Climate. The divergence may be due to both the underestimation of the April dust outbreak and the reappearance of the dusty layer formed on the 19th of February event (around 8 April) after ablation of the overlying layers (Fig. 8). This assumption could explain why near-surface impurity contents fit the measurements before 3 April and diverge after this date. The upper panel of Fig. 4 points out that C5 improves the simulated late-season near-surface impurity concentrations compared to all other configurations. However, in order to test this hypothesis a more detailed evaluation of the LAI (BC and dust) contents in snow should be performed using direct measurements of LAI and not LAI content estimated from (hyper)spectral measurements (e.g., Warren, 2013) which are uncertain for low impurity content (Dumont et al., 2017), but this is beyond the scope of the present study.

The divergence of the late-season near-surface LAI concentrations may also come from the impact of the neglected LAI types such as organic debris (which are present at the Col de Porte) or brown carbon. Additional chemical analyses would be required to investigate both of these assumptions.

Lastly, it should be noted that the wet deposition fluxes from ALADIN-Climate are only taken into account in the simulations when in situ precipitation is measured. Consequently, any mismatch between ALADIN-Climate and measured precipitation occurrence may lead to errors in simulated wet-deposited LAI content.

\subsection{Impact on Crocus melting rate}

Through the new developments implemented in Crocus we evaluate the impact of LAIs on the melting rate for the 20132014 snow season at the Col de Porte. We show that the meltout date of the snowpack advances by 6 to 9 days when accounting for radiative impact of impurities in snow (Fig. 3).

In the reference version of Crocus (C0), LAIs in snow are implicitly taken into account by decreasing the albedo in visible wavelengths as snow ages. This albedo decrease has been implemented to empirically fit the snow melting rate under meteorological conditions observed at the Col de Porte, which has been the main evaluation site of the Crocus model. This explains why the initial version is in agreement with the observations and the new developments do not imply a direct visible improvement. However, as illustrated by Lafaysse et al. (2017), this albedo parameterization and the calibration of its characteristic time constant are rather uncertain. This uncertainty is addressed by the physically based parameterization presented in this study which can moreover account for regional and temporal variability of LAI deposition.

When using the TARTES radiative transfer model, the impurities are explicitly taken into account and there is no empirical albedo reduction due to snow aging. This explains 

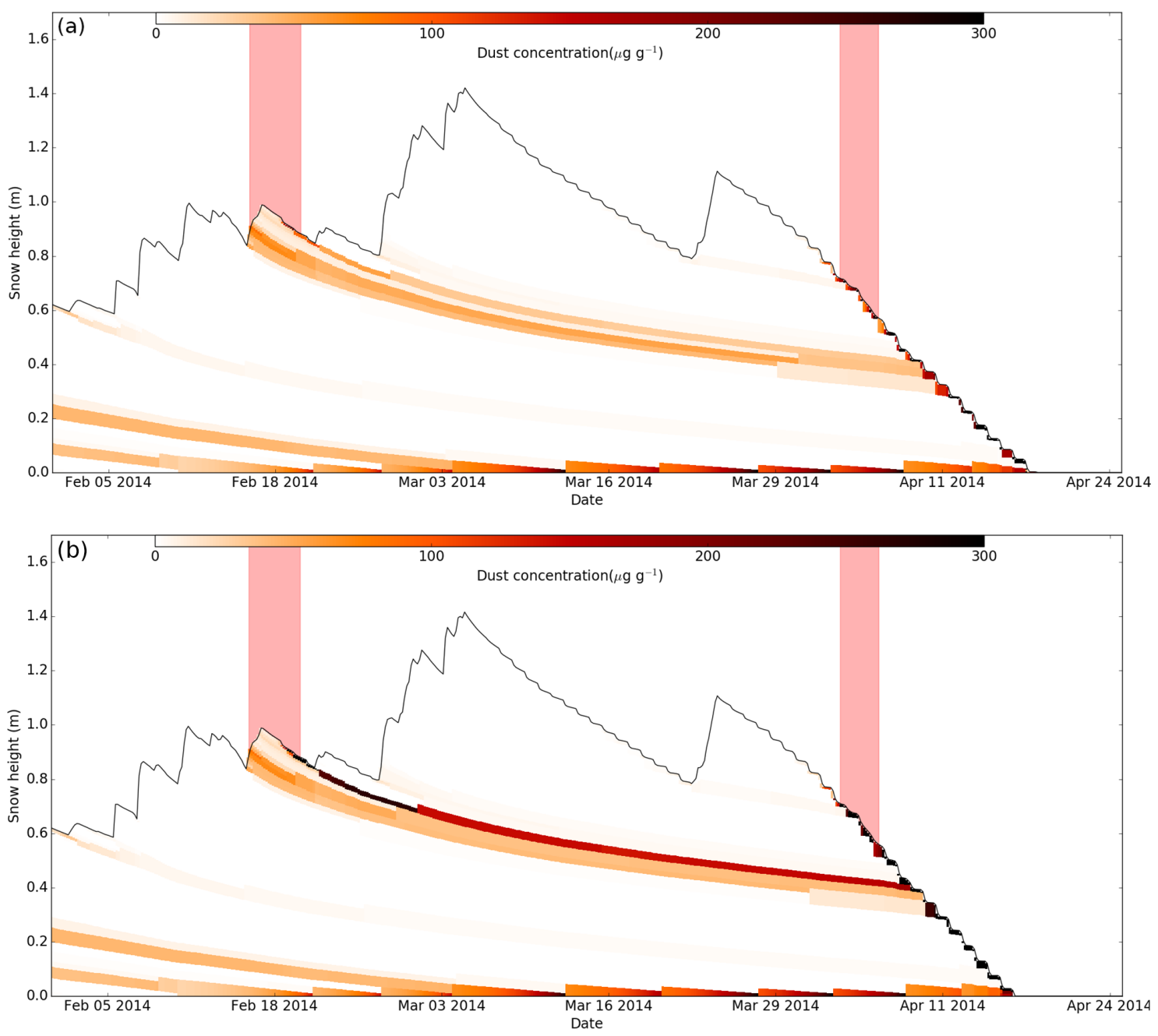

Figure 8. Simulated dust concentration profile for the second half of the 2013-2014 snow season at the Col de Porte. Panel (a) shows the configuration C2 using ALADIN-Climate deposition fluxes. Panel (b) shows the C5 configuration using the same parameters but ALADINClimate deposition fluxes have been modified to reproduce the measurements by Di Mauro et al. (2015). The two major Saharan dust events are represented by the red areas.

why the $\mathrm{C} 1$ configuration (TARTES without impurities) underestimates the melting rate. The inclusion of impurities improves albedo computation and in turn snow melting rate at the end of the season. The atmospheric deposition fluxes provided by ALADIN-Climate (C2,C3 and C4) improve the melting rate at the end of the season compared to $\mathrm{C} 1$ simulation, although SWE is simulated more accurately using $\mathrm{C} 1$, probably due to a bias at the beginning of the season. The second column of Table 2 presents RMSE on snow depths for the end of the season (January to melt). RMSE is around $6 \mathrm{~cm}$ for $\mathrm{C} 0, \mathrm{C} 2, \mathrm{C} 3$ and $\mathrm{C} 4$, showing that similar results are obtained in terms of the late-season melting rate with both the new physically based albedo scheme described in this study and the empirically based original scheme. A comparison in other sites is more likely to show discrepancies between the two approaches as the original scheme was calibrated at the Col de Porte.

However, even if C5 improves the near-surface impurity concentration, the melting rate increases too much, which worsens the SWE and snow depth simulations. A better simulation of the amount of LAIs in snow thus leads to the overestimation of the melt rate. This may come from the high equifinality in snowpack modeling as pointed out in the conclusion of Lafaysse et al. (2017). Indeed snowpack models contain several empirical parameterizations, each introducing modeling errors counterbalancing each other and yielding consistent results. For this reason, improving a process in the snow model does not necessarily improve the snowpack simulations. 


\subsection{Direct and indirect radiative impact of LAIs}

We estimate that over the whole season of 2013-2014, about $15 \%$ of the LAI radiative forcing comes from the indirect impact while $85 \%$ is due to the direct impact for the $\mathrm{C} 2$ configuration. This means that models which do not represent snow metamorphism and only account for the direct impact of LAIs underestimate by approximately $15 \%$ the radiative forcing of LAIs on snowpacks with similar characteristics to the Col de Porte. These results are close to the ones presented in Chapter 5 of Skiles (2014) showing that, in the upper Colorado basin, $80 \%$ of LAI radiative forcing comes from the direct impact as opposed to $20 \%$ for the indirect impact. The discrepancy is small and might be explained by the differences between the two studies (e.g., different LAI type, different atmospheric conditions, different snow SSA and different unfolding of the season) as the relative contributions of direct and indirect impacts have a period and site dependency.

When looking at the lower panel in Fig. 7 we can see some patterns in the evolution of the percentage of indirect impact according to SSA. Indeed, after a snowfall (resulting in high surface SSA), the SSA decreases quickly due to accelerated snow metamorphism. In this period of fast metamorphism the indirect impact is particularly high (up to $60 \%$ on 7 March) because the small additional energy income due to LAIs in fresh snow leads to an accelerated SSA decrease. After reaching a value around $10 \mathrm{~m}^{2} \mathrm{~kg}^{-1}$, SSA decreases much slower and the indirect impact becomes small (below 10\%). Then, from 13 March the snowpack is affected by a period of intensive melt, leading to low SSA (around $8 \mathrm{~m}^{2} \mathrm{~kg}^{-1}$ ). This SSA decrease is amplified by LAI radiative forcing as surface LAI content at the surface is relatively high during this period (Fig. 4), leading to even lower SSA. This additional SSA decrease caused by LAIs cause an increased indirect LAI radiative forcing (up to $25 \%$ on 20 March). We can then observe the same pattern around 15 April.

\subsection{Shortwave albedo computation}

Section 4.4 highlights that shortwave albedo computation features a significant bias for all the configurations, which was also noticed by Lafaysse et al. (2017) regardless of the albedo scheme employed. Snow albedo is not only dependent on snow LAI contents but also largely depends on SSA values, which have been shown to exhibit a $4 \mathrm{~m}^{2} \mathrm{~kg}^{-1}$ bias for near-surface snow. The additional computation run using optimized SSA values indicates that most of the albedo bias is due to the bias in SSA (last column of Table 2). Modifications of other Crocus parameterizations (such as the SSA evolution laws) would therefore be required to significantly improve shortwave albedo computations.

Section 4.4 also points out that our recent developments do not improve the albedo computation compared to the reference version ( $\mathrm{C} 0$ compared to $\mathrm{C} 2, \mathrm{C} 3, \mathrm{C} 4$ and $\mathrm{C} 5$ ). However, these developments are expected to improve Crocus shortwave albedo computations if they were applied to regions with different contamination levels of LAIs compared to the Col de Porte (e.g., Colorado, the Arctic, the Antarctic) where the reference empirical albedo scheme calibrated at the $\mathrm{Col}$ de Porte performs poorly.

Finally, as underlined in Lafaysse et al. (2017), the improvement of one parameterization does not necessarily lead to the improvement of the overall snow simulations. For example, snow depth evolution at the Col de Porte is reasonably simulated despite a strong shortwave albedo overestimation. This albedo bias is compensated by other parameterization biases; correcting this bias would hence lead to a degradation of the snowpack simulation if the other parameterizations remain unmodified (e.g., C5 compared to C2, C3 and C4).

\subsection{Model limitations}

The parameterization of liquid water content in Crocus follows a simple conceptual bucket approach which does not accurately represent the evolution of liquid water content in the snowpack, as pointed out in Lafaysse et al. (2017). Work is in progress to include a physically based liquid water parameterization in Crocus (D'Amboise et al., 2017). Changing the liquid water content parameterization is expected to improve the modeling of water percolation and impact the scavenging of LAIs in the snowpack. Indeed physically based approaches induce much more heterogeneous repartition of the liquid water content at melt time than the bucket approach (e.g., due to the representation of capillarity barriers; Wever et al., 2014). We would therefore expect a more realistic and heterogeneous LAI repartition after scavenging.

Concerning atmospheric radiative transfer (Sect. 2.3), ATMOTARTES only has a rough representation of the effect of LAIs in the atmosphere (one type of aerosols and constant vertical profile). This could be extended as in SBDART (Ricchiazzi et al., 1998) but the impact would be limited while the numerical cost would be significantly increased.

Several model and parameter choices relative to in-snow radiative transfer also contain some limitations. First, here we use the ice refractive index value proposed in Warren and Brandt (2008), but alternative parameterizations could also be used (e.g., the visible range parameterization proposed in the recent study of Picard et al., 2016a) and impact the results. Secondly, LAIs are represented as Rayleigh scatterers in TARTES (their size is assumed much smaller than the wavelength). This theory is acceptable in the case of BC but may not perfectly apply to dust, depending on its volume size distribution, and may lead to an underestimation of dust radiative impacts. Coulter measurements show that the average diameter according to their volume contribution for our dust is $2.8 \mu \mathrm{m}$, which indeed suggests that dust radiative impact is underestimated here and calls for another parameterization of LAI impacts in TARTES for dust particles. Finally, in the present study LAIs are assumed to be exter- 
nally mixed to the ice matrix. Flanner et al. (2012) showed that internally mixed $\mathrm{BC}$ was up to $80 \%$ more absorptive than externally mixed BC. Recently, Liou et al. (2014) and He et al. (2014) also pointed out that both impurities-snow internal mixing and snow nonsphericity play very important roles in snow albedo calculations. They showed that internal mixing can enhance $\mathrm{BC}$-induced snow albedo reduction up to $50 \%$ compared with external mixing. This enhancement is stronger for nonspherical ice elements than ice spheres, although ice spheres still have a larger absolute albedo reduction than nonspherical ice elements under the same BC content in snow. Introducing an internally mixed representation of LAIs in TARTES could in turn impact the results. However, a better knowledge of the partition between internally and externally mixed LAIs in seasonal snowpacks would be required to accurately characterize the impact of this variable.

\section{Conclusion and outlooks}

In this study, new developments aiming at modeling the deposition and the evolution of light-absorbing impurities within the snowpack are introduced in the detailed snowpack model Crocus. We implemented the dry and wet deposition of a user-defined number of LAI species. The deposition fluxes can either be extracted from an atmospheric model as in this study or forced by user-prescribed deposition rates as in Charrois et al. (2016). The fate of the aerosols deposited in the snow is computed by mass-conservation evolution laws for impurity mass content as snowpack evolves. Finally, we use the radiative transfer model TARTES embedded into Crocus to explicitly account for the direct and indirect radiative impact of the LAIs evolving in the snowpack.

This newly implemented Crocus version was then evaluated with field measurements performed at the Col de Porte experimental site (French Alps) near Grenoble, during the 2013-2014 snow year. For this evaluation we accounted for two LAI species assumed to have the strongest radiative impact on snow: BC and mineral dust. We extracted aerosol deposition fluxes from the atmospheric model ALADINClimate and forced the snowpack model with these deposition values. We evaluate the relevance of using atmospheric aerosol with a physically based model in terms of near-surface impurity concentration, near-surface SSA, snow depth and SWE. It appears that the atmospheric model ALADIN-Climate as a forcing dataset simulates LAI deposition acceptably over a season despite a large underestimation of extreme dust outbreaks and an overestimation of $\mathrm{BC}$ deposition. Radiative transfer properties of a seasonal snowpack in the presence of dust and $\mathrm{BC}$ can be computed efficiently following a physically based approach coupled to atmospheric aerosol deposition fluxes. The impact of LAIs in terms of snow height and SWE is significant. Indeed, depending on the configuration chosen for LAI parameters, com- plete snow melt-out date advances by 6 to 9 days in comparison with the pure snow simulation. This impact on snow melting is of crucial importance for hydrological concerns. We also estimate the direct/indirect proportion of LAI radiative forcing. For the Col de Porte in this particular season $85 \%$ of the radiative forcing of LAIs in snow comes from the direct impact (darkening of the snow) against $15 \%$ for the indirect impact (enhanced metamorphism). This means that models representing the LAI radiative impact of snow without accounting for the metamorphism underestimate the total impact by $15 \%$. Moreover at daily resolution, the relative proportion of direct and indirect impacts can vary widely, showing evolution patterns related to SSA evolution.

Our study highlights the need for intensive field campaigns to better evaluate these new developments and better understand these processes. Some parameters of our newly implemented version still need to be adjusted towards field data that are currently missing. Concomitant measurements of snow temperature, SSA, accumulation of soot and dust, and spectral albedo at different sites would provide a stronger basis for defining model parameters and evaluating it. For example, a direct evaluation of the dust and $\mathrm{BC}$ contents is required to quantify more precisely their respective part in the shortening of the snow season.

We showed that the use of atmospheric aerosol deposition fluxes provided by ALADIN-Climate coupled with the recent developments of Crocus leads to a reasonable estimation of snow surface impurity content. Even if this estimation is not perfect due to modeling uncertainties and atmospheric model horizontal resolution, it gives a first guess of LAI impacts on snow spectral albedo. This first guess is a crucial point for assimilating optical reflectance measurements in a snowpack model, although a better quantification of the errors in the impurity forcing and modeling will be required (Charrois et al., 2016).

This study is one of the first attempts to account for the deposition and the evolution of impurities in a detailed snowpack model. Here we investigate the effect of dust and BC on snow radiative properties at the $\mathrm{Col}$ de Porte experimental site but our model can apply to any snow-covered regions affected by LAIs. This model could be used in dustaffected areas (e.g., Colorado or Himalaya) or BC-affected regions (e.g., Arctic or Antarctic regions for climate studies). It could also be used to assess the impact of ashes on snow in volcanic regions (e.g., Iceland). Moreover, Crocus provides habitat data for in-snow ecological modeling (e.g., snow temperature, liquid water content). The computation of nutrient evolution in the snowpack could be performed using the recent developments presented in this study. Then, it appears possible to model algae growth, evolution and radiative impacts (Cook et al., 2017) on the snowpack.

Finally, Crocus is now capable of tracking thin layers highly concentrated in LAIs (e.g., Saharan dust outbreaks) in the snowpack and representing the discontinuity induced in terms of energy absorption and thus snow metamorphism. 
Our new developments could then be used to address numerically the frequently asked question: "Is there a link between dust outbreaks and avalanche hazard?" (Landry, 2014; Chomette et al., 2016).

Code and data availability. The code used in this study was developed inside the open source SURFEX project (http://www.umr-cnrm.fr/surfex). While it is not implemented in an official SURFEX release, the code can be downloaded from a specific tag of the git repository maintained by Centre d'Études de la Neige. For reproducibility of results, the version used in this work is tagged as "tuzetTCD17" on the SURFEX git repository (git.umr-cnrm.fr/git/Surfex_Git2.git). The full procedure and documentation to access this git repository can be found at https: //opensource.cnrm-game-meteo.fr/projects/snowtools_git/wiki.

The Col de Porte dataset is available on the PANGAEA repository (https://doi.org/10.1594/PANGAEA.774249; Morin et al., 2012b) as well as on the public ftp server ftp://ftp-cnrm.meteo.fr/pub-cencdp. Time series of snow spectral albedo and superficial snow specific surface area and impurity content are available through the PANGAEA database (https://doi.org/10.1594/PANGAEA.874272, Picard et al., 2017).

Author contributions. MD and FT coordinated the study. FT, MD, LC, ML and SM implemented and tested the new developments in the Crocus snowpack model. MD developed the near-surface properties computation algorithm. GP and LA developed and built the automatic albedometer. GP, LA, SM and DV deployed it at the Col de Porte. DV performed the impurity content measurements. PN provided the ALADIN-Climate simulations and YL provided the snow and meteorological measurements at the Col de Porte. FT prepared the manuscript with contributions and feedbacks from the other authors.

Competing interests. The authors declare that they have no conflict of interest.

Acknowledgements. CNRM-CEN and IGE are part of Labex OSUG@2020 (investissement d'avenir - ANR10 LABX56). This study was supported by the ANR programs 1-JS56-005-01 MONISNOW and ANR-16-CE01-0006 EBONI, the INSU-LEFE projects BON and ASSURANCE, and the Ecole Doctorale SDU2E of Toulouse. The authors are grateful to the Col de Porte and EDF-DTG staff for ensuring the proper functioning of all the instruments and to Lydie Mbemba for the in situ measurements of impurity content.

Edited by: Christian Haas

Reviewed by: three anonymous referees

\section{References}

Aoki, T., Motoyoshi, H., Kodama, Y., Yasunari, T. J., Sugiura, K., and Kobayashi, H.: Atmospheric aerosol deposition on snow surfaces and its effect on albedo, Sola, 2, 13-16, 2006.

Aoki, T., Kuchiki, K., Niwano, M., Kodama, Y., Hosaka, M., and Tanaka, T.: Physically based snow albedo model for calculating broadband albedos and the solar heating profile in snowpack for general circulation models, J. Geophys. Res., 116, D11, https://doi.org/10.1029/2010JD015507, 2011.

Aoki, T., Matoba, S., Yamaguchi, S., Tanikawa, T., Niwano, M., Kuchiki, K., Adachi, K., Uetake, J., Motoyama, H., and Hori, M.: Light-absorbing snow impurity concentrations measured on Northwest Greenland ice sheet in 2011 and 2012, Bulletin of Glaciological Research, 32, 21-31, 2014.

Bird, R. E. and Riordan, C.: Simple solar spectral model for direct and diffuse irradiance on horizontal and tilted planes at the earth's surface for cloudless atmospheres, J. Clim. Appl. Meteorol., 25, 87-97, 1986.

Bisiaux, M. M., Edwards, R., McConnell, J. R., Curran, M. A. J., Van Ommen, T. D., Smith, A. M., Neumann, T. A., Pasteris, D. R., Penner, J. E., and Taylor, K.: Changes in black carbon deposition to Antarctica from two high-resolution ice core records, 1850-2000 AD, Atmos. Chem. Phys., 12, 4107-4115, https://doi.org/10.5194/acp-12-4107-2012, 2012.

Brun, E., Martin, E., Simon, V., Gendre, C., and Coléou, C.: An energy and mass model of snow cover suitable for operational avalanche forecasting, J. Glaciol., 35, 333-342, 1989.

Brun, E., David, P., Sudul, M., and Brunot, G.: A numerical model to simulate snow-cover stratigraphy for operational avalanche forecasting, J. Glaciol., 38, 13-22, 1992.

Bubnova, R., Hello, G., Bernard, P., and Geleyn, J.: Integration of the fully elastic equations cast in the hydrostatic pressure terrainfollowing coordinate in the framework of the ARPEGE/Aladin NWP system, Mon. Weather Rev., 123, 515-535, 1995.

Bucholtz, A.: Rayleigh-scattering calculations for the terrestrial atmosphere, Appl. Opt., 34, 2765-2773, 1995.

Carmagnola, C. M., Domine, F., Dumont, M., Wright, P., Strellis, B., Bergin, M., Dibb, J., Picard, G., Libois, Q., Arnaud, L., and Morin, S.: Snow spectral albedo at Summit, Greenland: measurements and numerical simulations based on physical and chemical properties of the snowpack, The Cryosphere, 7, 1139-1160, https://doi.org/10.5194/tc-7-1139-2013, 2013.

Carmagnola, C. M., Morin, S., Lafaysse, M., Domine, F., Lesaffre, B., Lejeune, Y., Picard, G., and Arnaud, L.: Implementation and evaluation of prognostic representations of the optical diameter of snow in the SURFEX/ISBA-Crocus detailed snowpack model, The Cryosphere, 8, 417-437, https://doi.org/10.5194/tc8-417-2014, 2014.

Chang, H. and Charalampopoulos, T.: Determination of the wavelength dependence of refractive indices of flame soot, P. Roy. Soc. Lond. A Mat., 430, 577-591, 1990.

Charrois, L., Cosme, E., Dumont, M., Lafaysse, M., Morin, S., Libois, Q., and Picard, G.: On the assimilation of optical reflectances and snow depth observations into a detailed snowpack model, The Cryosphere, 10, 1021-1038, https://doi.org/10.5194/tc-10-1021-2016, 2016.

Chomette, L., Bacardit, M., Gavaldà, J., Dumont, M., Tuzet, F., and Moner, I.: Effects of Saharan dust outbreaks on the snow sta- 
bility in the Pyrenees, in: Proceedings of the International Snow Science Workshop (ISSW), 2016.

Clifton, A., Manes, C., Rüedi, J.-D., Guala, M., and Lehning, M.: On shear-driven ventilation of snow, Bound.-Lay. Meteorol., 126, 249-261, 2008.

Conway, H., Gades, A., and Raymond, C.: Albedo of dirty snow during conditions of melt, Water Resour. Res., 32, 1713-1718, 1996.

Cook, J., Hodson, A., Taggart, A., Mernild, S., and Tranter, M.: A predictive model for the spectral "bioalbedo" of snow, J. Geophys. Res.-Earth, 122, 434-454, 2017.

D’Amboise, C. J. L., Müller, K., Oxarango, L., Morin, S., and Schuler, T. V.: Implementation of a physically based water percolation routine in the Crocus/SURFEX (V7.3) snowpack model, Geosci. Model Dev., 10, 3547-3566, https://doi.org/10.5194/gmd-10-3547-2017, 2017.

De Angelis, M. and Gaudichet, A.: Saharan dust deposition over Mont Blanc (French Alps) during the last 30 years, Tellus B, 43, 61-75, 1991.

Dee, D. P., Uppala, S. M., Simmons, A. J., Berrisford, P., Poli, P., Kobayashi, S., Andrae, U., Balmaseda, M. A., Balsamo, G., Bauer, P., Bechtold, P., Beljaars, A. C. M., van de Berg, L., Bidlot, J., Bormann, N., Delsol, C., Dragani, R., Fuentes, M., Geer, A. J., Haimberger, L., Healy, S. B., Hersbach, H., Hólm, E. V., Isaksen, L., Kålberg, P., Köhler, M., Matricardi, M., McNally, A. P., Monge-Sanz, B. M., Morcrette, J.-J., Park, B.-K., Peubey, C., de Rosnay, P., Tavolato, C., Thépaut, J.-N., and Vitart, F.: The ERA-Interim reanalysis: configuration and performance of the data assimilation system, Q. J. Roy. Meteor. Soc., 137, 553-597, https://doi.org/10.1002/qj.828, 2011.

Di Mauro, B., Fava, F., Ferrero, L., Garzonio, R., Baccolo, G., Delmonte, B., and Colombo, R.: Mineral dust impact on snow radiative properties in the European Alps combining ground, UAV, and satellite observations, J. Geophys. Res.-Atmos., 120, 60806097, 2015.

Doherty, S. J., Warren, S. G., Grenfell, T. C., Clarke, A. D., and Brandt, R. E.: Light-absorbing impurities in Arctic snow, Atmos. Chem. Phys., 10, 11647-11680, https://doi.org/10.5194/acp-1011647-2010, 2010.

Doherty, S. J., Grenfell, T. C., Forsström, S., Hegg, D. L., Brandt, R. E., and Warren, S. G.: Observed vertical redistribution of black carbon and other insoluble light-absorbing particles in melting snow, J. Geophys. Res.-Atmos., 118, 5553-5569, 2013.

Domine, F., Salvatori, R., Legagneux, L., Salzano, R., Fily, M., and Casacchia, R.: Correlation between the specific surface area and the short wave infrared (SWIR) reflectance of snow: preliminary investigation, Cold Reg. Sci. Technol., 46, 60-68, https://doi.org/10.1016/j.coldregions.2006.06.002, 2006.

Dumont, M., Arnaud, L., Picard, G., Libois, Q., Lejeune, Y., Nabat, P., Voisin, D., and Morin, S.: In situ continuous visible and nearinfrared spectroscopy of an alpine snowpack, The Cryosphere, 11, 1091-1110, https://doi.org/10.5194/tc-11-1091-2017, 2017.

Flanner, M., Liu, X., Zhou, C., and Penner, J.: Enhanced solar energy absorption by internally-mixed black carbon in snow grains, Atmos. Chem. Phys., 12, 4699-4721, https://doi.org/10.5194/acp-12-4699-2012, 2012.

Flanner, M. G. and Zender, C. S.: Snowpack radiative heating: Influence on Tibetan Plateau climate, Geophys. Res. Lett., 32, L06501, https://doi.org/10.1029/2004GL022076, 2005.
Flanner, M. G., Zender, C. S., Randerson, J. T., and Rasch, P. J.: Present-day climate forcing and response from black carbon in snow, J. Geophys. Res., 112, D11202, https://doi.org/10.1029/2006JD008003, 2007.

Ginot, P., Dumont, M., Lim, S., Patris, N., Taupin, J.-D., Wagnon, P., Gilbert, A., Arnaud, Y., Marinoni, A., Bonasoni, P., and Laj, P.: A 10 year record of black carbon and dust from a Mera Peak ice core (Nepal): variability and potential impact on melting of Himalayan glaciers, The Cryosphere, 8, 1479-1496, https://doi.org/10.5194/tc-8-1479-2014, 2014.

He, C., Li, Q., Liou, K.-N., Takano, Y., Gu, Y., Qi, L., Mao, Y., and Leung, L. R.: Black carbon radiative forcing over the Tibetan Plateau, Geophys. Res. Lett., 41, 7806-7813, 2014.

Hess, M., Koepke, P., and Schult, I.: Optical properties of aerosols and clouds: The software package OPAC, B. Am. Meteorol. Soc., 79, 831-844, 1998.

Jacobi, H.-W., Lim, S., Ménégoz, M., Ginot, P., Laj, P., Bonasoni, P., Stocchi, P., Marinoni, A., and Arnaud, Y.: Black carbon in snow in the upper Himalayan Khumbu Valley, Nepal: observations and modeling of the impact on snow albedo, melting, and radiative forcing, The Cryosphere, 9, 1685-1699, https://doi.org/10.5194/tc-9-1685-2015, 2015.

Jacobson, M.-Z.: Climate response of fossil fuel and biofuel soot, accounting for soot's feedback to snow and sea ice albedo and emissivity, J. Geophys. Res., 109, D21 201, https://doi.org/10.1029/2004JD004945, 2004.

Jiménez-Aquino, J. and Varela, J.: Two stream approximation to radiative transfer equation: An alternative method of solution, Revista mexicana de física, 51, 82-86, 2005.

Justus, C. G. and Paris, M. V.: A model for solar spectral irradiance and radiance at the bottom and top of a cloudless atmosphere, J. Clim. Appl. Meteorol., 24, 193-205, 1985.

Kokhanovsky, A. and Zege, E.: Scattering optics of snow, Appl. Opt., 43, 1589-1602, https://doi.org/10.1364/AO.43.0001589, 2004.

Krinner, G., Boucher, O., and Balkanski, Y.: Ice-free glacial northern Asia due to dust deposition on snow, Clim. Dynam., 27, 613625, https://doi.org/10.1007/s00382-006-0159-z, 2006.

Lafaysse, M., Cluzet, B., Dumont, M., Lejeune, Y., Vionnet, V., and Morin, S.: A multiphysical ensemble system of numerical snow modelling, The Cryosphere, 11, 1173-1198, https://doi.org/10.5194/tc-11-1173-2017, 2017.

Landry, C. C.: DESERT DUST AND SNOW STABILITY, in: International Snow Science Workshops (ISSW) Proceedings of Professional Papers and Poster Talks, 2014.

Landry, C. C., Buck, K. A., Raleigh, M. S., and Clark, M. P.: Mountain system monitoring at Senator Beck Basin, San Juan Mountains, Colorado: A new integrative data source to develop and evaluate models of snow and hydrologic processes, Water Resour. Res., 50, 1773-1788, https://doi.org/10.1002/2013WR013711, 2014.

Lehning, M., Bartelt, P., Brown, B., Fierz, C., and Satyawali, P.: A physical SNOWPACK model for the Swiss avalanche warning. Part II: snow microstructure, Cold Reg. Sci. Technol., 35, 147167, https://doi.org/10.1016/S0165-232X(02)00073-3, 2002.

Libois, Q., Picard, G., France, J. L., Arnaud, L., Dumont, D., Carmagnola, C. M., and King, M. D.: Influence of grain shape on light penetration in snow, The Cryosphere, 7, 1803-1818, https://doi.org/10.5194/tc-7-1803-2013, 2013. 
Libois, Q., Picard, G., Arnaud, L., Morin, S., and Brun, E.: Modeling the impact of snow drift on the decameter-scale variability of snow properties on the Antarctic Plateau, J. Geophys. Res., 119, 11662-11681, https://doi.org/10.1002/2014JD022361, 2014.

Libois, Q., Picard, G., Arnaud, L., Dumont, M., Lafaysse, M., Morin, S., and Lefebvre, E.: Summertime evolution of snow specific surface area close to the surface on the Antarctic Plateau, The Cryosphere, 9, 2383-2398, https://doi.org/10.5194/tc-92383-2015, 2015.

Liou, K., Takano, Y., He, C., Yang, P., Leung, L., Gu, Y., and Lee, W.: Stochastic parameterization for light absorption by internally mixed BC/dust in snow grains for application to climate models, J. Geophys. Res.-Atmos., 119, 7616-7632, 2014.

Maître, A., Soulat, J.-M., Masclet, P., Stoklov, M., Marquès, M., and De Gaudemaris, R.: Exposure to carcinogenic air pollutants among policemen working close to traffic in an urban area, Scand. J. Work Env. Hea., 402-410, 2002.

Malinka, A., Zege, E., Heygster, G., and Istomina, L.: Reflective properties of white sea ice and snow, The Cryosphere, 10, 25412557, https://doi.org/10.5194/tc-10-2541-2016, 2016.

Malinka, A. V.: Light scattering in porous materials: Geometrical optics and stereological approach, J. Quant. Spectrosc. Ra., 141, 14-23, 2014.

Ménégoz, M., Krinner, G., Balkanski, Y., Boucher, O., Cozic, A., Lim, S., Ginot, P., Laj, P., Gallée, H., Wagnon, P., Marinoni, A., and Jacobi, H. W.: Snow cover sensitivity to black carbon deposition in the Himalayas: from atmospheric and ice core measurements to regional climate simulations, Atmos. Chem. Phys., 14, 4237-4249, https://doi.org/10.5194/acp-14-4237-2014, 2014.

Morin, S., Lejeune, Y., Lesaffre, B., Panel, J.-M., Poncet, D., David, P., and Sudul, M.: A 18-years long (1993-2011) snow and meteorological dataset from a mid-altitude mountain site (Col de Porte, France, $1325 \mathrm{~m}$ alt.) for driving and evaluating snowpack models, Earth Syst. Sci. Data, 4, 13-21, https://doi.org/10.5194/essd4-13-2012, 2012a.

Morin, S., Lejeune, Y., Lesaffre, B., Panel, J.-M., Poncet, D., David, P., and Sudul, M.: A 18-years long (1993-2011) snow and meteorological dataset from a mid-altitude mountain site (Col de Porte, France, 1325 altitude), PANGAEA, https://doi.org/10.1594/PANGAEA.774249, 2012b.

Müller, T., Schladitz, A., Kandler, K., and Wiedensohler, A.: Spectral particle absorption coefficients, single scattering albedos and imaginary parts of refractive indices from ground based in situ measurements at Cape Verde Island during SAMUM-2, Tellus B, 63, 573-588, 2011.

Nabat, P., Somot, S., Mallet, M., Michou, M., Sevault, F., Driouech, F., Meloni, D., di Sarra, A., Di Biagio, C., Formenti, P., Sicard, M., Léon, J.-F., and Bouin, M.-N.: Dust aerosol radiative effects during summer 2012 simulated with a coupled regional aerosol-atmosphere-ocean model over the Mediterranean, Atmos. Chem. Phys., 15, 3303-3326, https://doi.org/10.5194/acp15-3303-2015, 2015.

Nicolet, M.: On the molecular scattering in the terrestrial atmosphere: An empirical formula for its calculation in the homosphere, Planet. Space Sci., 32, 1467-1468, 1984.

Niwano, M., Aoki, T., Kuchiki, K., Hosaka, M., and Kodama, Y.: Snow Metamorphism and Albedo Process (SMAP) model for climate studies: Model validation using meteorological and snow impurity data measured at Sapporo, J. Geophys. Res., 117, F03008, https://doi.org/10.1029/2011JF002239, 2012.

Painter, T. H., Barrett, A. P., Landry, C. C., Neff, J. C., Cassidy, M. P., Lawrence, C. R., McBride, K. E., and Farmer, G. L.: Impact of disturbed desert soils on duration of mountain snow cover, Geophys. Res. Lett., 34, 12, 2007.

Painter, T. H., Deems, J. S., Belnap, J., Hamlet, A. F., Landry, C. C., and Udall, B.: Response of Colorado River runoff to dust radiative forcing in snow, P. Natl. Acad. Sci. USA, 107, 17125-17130, https://doi.org/10.1073/pnas.0913139107, 2010.

Painter, T. H., Flanner, M. G., Kaser, G., Marzeion, B., VanCuren, R. A., and Abdalati, W.: End of the Little Ice Age in the Alps forced by industrial black carbon, P. Natl. Acad. Sci. USA, 110, 15216-15221, 2013a.

Painter, T. H., Seidel, F. C., Bryant, A. C., McKenzie Skiles, S., and Rittger, K.: Imaging spectroscopy of albedo and radiative forcing by light-absorbing impurities in mountain snow, J. Geophys. Res.-Atmos., 118, 9511-9523, 2013 b.

Picard, G., Libois, Q., and Arnaud, L.: Refinement of the ice absorption spectrum in the visible using radiance profile measurements in Antarctic snow, The Cryosphere, 10, 2655-2672, https://doi.org/10.5194/tc-10-2655-2016, 2016a.

Picard, G., Libois, Q., Arnaud, L., Verin, G., and Dumont, M.: Development and calibration of an automatic spectral albedometer to estimate near-surface snow SSA time series, The Cryosphere, 10, 1297-1316, https://doi.org/10.5194/tc-10-1297-2016, $2016 \mathrm{~b}$.

Picard, G., Arnaud, L., and Dumont, M.: Time-series of snow spectral albedo and superficial snow specific surface area and impurity content at Col de Porte, French Alps, 2014, PANGAEA, https://doi.org/10.1594/PANGAEA.874272, 2017.

Polashenski, C. M., Dibb, J. E., Flanner, M. G., Chen, J. Y., Courville, Z. R., Lai, A. M., Schauer, J. J., Shafer, M. M., and Bergin, M.: Neither dust nor black carbon causing apparent albedo decline in Greenland's dry snow zone: Implications for MODIS C5 surface reflectance, Geophys. Res. Lett., 42, 93199327, 2015.

Ricchiazzi, P., Yang, S., Gautier, C., and Sowle, D.: SBDART: A research and teaching software tool for plane-parallel radiative transfer in the Earth's atmosphere, B. Am. Meteorol. Soc., 79, 2101-2114, 1998.

Skiles, M., Painter, T., and Okin, G.: A Method to Retrieve the Complex Refractive Index and Single Scattering Optical Properties of Dust Deposited in Mountain Snow Cover, in: AGU Fall Meeting Abstracts, 1, 0423, 2014.

Skiles, S. M.: Dust and black carbon radiative forcing controls on snowmelt in the Colorado River Basin, PhD thesis, 2014.

Skiles, S. M., Painter, T. H., Belnap, J., Holland, L., Reynolds, R. L., Goldstein, H. L., and Lin, J.: Regional variability in dust-onsnow processes and impacts in the Upper Colorado River Basin, Hydrol. Process., 29, 5397-5413, 2015.

Stamnes, K., Tsay, S.-C., Wiscombe, W., and Jayaweera, K.: Numerically stable algorithm for discrete-ordinate-method radiative transfer in multiple scattering and emitting layered media, Appl. Opt., 27, 2502-2509, 1988.

Sterle, K. M., McConnell, J. R., Dozier, J., Edwards, R., and Flanner, M. G.: Retention and radiative forcing of black carbon in eastern Sierra Nevada snow, The Cryosphere, 7, 365-374, https://doi.org/10.5194/tc-7-365-2013, 2013. 
Takeuchi, N.: Surface albedo and characteristics of cryoconite (biogenic surface dust) on an Alaska glacier, Gulkana Glacier in the Alaska Range, Bulletin of glaciological research, 19, 63-70, 2002.

Toon, O. B., McKay, C., Ackerman, T., and Santhanam, K.: Rapid calculation of radiative heating rates and photodissociation rates in inhomogeneous multiple scattering atmospheres, J. Geophys. Res.-Atmos., 94, 16287-16301, 1989.

Varga, G., Újvári, G., and Kovács, J.: Spatiotemporal patterns of Saharan dust outbreaks in the Mediterranean Basin, Aeolian Res., 15, 151-160, 2014.

Vionnet, V., Brun, E., Morin, S., Boone, A., Martin, E., Faroux, S., Moigne, P. L., and Willemet, J.-M.: The detailed snowpack scheme Crocus and its implementation in SURFEX v7.2, Geosci. Model. Dev., 5, 773-791, https://doi.org/10.5194/gmd5-773-2012, 2012.

Warren, S.: Optical properties of snow, Rev. Geophys., 20, 67-89, https://doi.org/10.1029/RG020i001p00067, 1982.

Warren, S. and Brandt, R.: Optical constants of ice from the ultraviolet to the microwave: A revised compilation, J. Geophys. Res., 113, D14220, https://doi.org/10.1029/2007JD009744, 2008.
Warren, S. G.: Can black carbon in snow be detected by remote sensing?, J. Geophys. Res.-Atmos., 118, 779-786, https://doi.org/10.1029/2012JD018476, 2013.

Warren, S. G. and Wiscombe, W.: A Model for the Spectral Albedo of Snow. II: Snow Containing Atmospheric Aerosols, J. Atmos. Sci., 37, 2734-2745, 1980.

Wever, N., Fierz, C., Mitterer, C., Hirashima, H., and Lehning, M.: Solving Richards Equation for snow improves snowpack meltwater runoff estimations in detailed multi-layer snowpack model, The Cryosphere, 8, 257-274, https://doi.org/10.5194/tc-8-2572014, 2014.

Wiscombe, W. J. and Warren, S. G.: A model for the spectral albedo of snow. I: Pure snow, J. Atmos. Sci., 37, 2712-2733, 1980.

Yang, S., Xu, B., Cao, J., Zender, C. S., and Wang, M.: Climate effect of black carbon aerosol in a Tibetan Plateau glacier, Atmos. Environ., 111, 71-78, 2015. 